Review

\title{
Durability and Sustainability of Cement-Stabilized Materials Based on Utilization of Waste Materials: A Literature Review
}

\author{
Penghui Wen ${ }^{1}$, Chaohui Wang ${ }^{1, *}$, Liang Song ${ }^{2}$, Liangliang $\mathrm{Niu}^{1}$ and Haoyu Chen ${ }^{1}$ \\ 1 School of Highway, Chang'an University, Xi'an 710064, China; 2019021008@chd.edu.cn (P.W.); \\ 2019121183@chd.edu.cn (L.N.); 2019321031@chd.edu.cn (H.C.) \\ 2 Xinjiang Transportation Planning Surveying and Design Institute, Urumqi 830006, China; \\ 2015021059@chd.edu.cn \\ * Correspondence: wchh0205@chd.edu.cn
}

check for updates

Citation: Wen, P.; Wang, C.; Song, L.; Niu, L.; Chen, H. Durability and Sustainability of Cement-Stabilized Materials Based on Utilization of Waste Materials: A Literature Review. Sustainability 2021, 13, 11610. https:// doi.org/10.3390/su132111610

Academic Editors: Castorina Wang, Castorina Silva Vieira and Andrew Shing-Tao Chang

Received: 14 September 2021

Accepted: 9 October 2021

Published: 20 October 2021

Publisher's Note: MDPI stays neutral with regard to jurisdictional claims in published maps and institutional affiliations.

Copyright: (c) 2021 by the authors. Licensee MDPI, Basel, Switzerland. This article is an open access article distributed under the terms and conditions of the Creative Commons Attribution (CC BY) license (https:// creativecommons.org/licenses/by/ $4.0 /)$.

\begin{abstract}
The utilization of waste materials in cement-stabilized materials (CSMs) is an important way to promote the sustainable development of road engineering construction and solve the environmental problems caused by the accumulation of waste materials. With the increasingly prominent global environmental problems, the exploitation of natural aggravate and the production of cement are subject to strict management and restrictions. Different waste materials, such as industrial and mining wastes, construction and demolition wastes, municipal wastes, waste rubber and waste fiber, are utilized in CSMs, and this is beneficial to promote the sustainable development of CSMs. In order to promote the rational application of waste materials in CSMs, this paper systematically reviews the research on the durability and sustainable development of CSMs. The types and mixing forms of waste materials reutilized in CSMs are discussed. The effect of different waste materials on the durability of CSMs is objectively evaluated. The potential challenges of sustainable development of CSMs are proposed. This review may help to alleviate the apprehension of road workers about the utilization of waste materials in CSMs and provide useful suggestions for the large-scale application of different waste materials.
\end{abstract}

Keywords: cement-stabilized materials; waste materials; durability; resource utilization; sustainability

\section{Introduction}

With the continuous increase in the number of highway construction projects worldwide, the consumption of natural building materials and the destruction of the environment has become increasingly prominent $[1,2]$. In the construction of highway engineering, cement-stabilized material (CSM) is widely applied in subgrade and base because of its excellent strength and low cost. Traditional CSMs are formed by mixing and rolling of cement, water, natural aggregate or fine-grained soil, and the consumption of natural building materials cannot be underestimated. When CSMs are utilized in base or subgrade, its bearing capacity and durability are very important to ensure the service quality of the pavement within the design service life. In the early design period of CSM structural layer, it is mainly to pursue high strength and high stiffness based on controlling cost. As scholars have more and more in-depth understanding of the failure mechanism of CSMs, CSMs which only be taken strength and stiffness as control requirements gradually appear the problem of insufficient durability, which seriously affects the integral performance of highway [3-5]. The reflection crack caused by the insufficient durability of CSMs is one of the most significant damages in the application [6]. The insufficient durability of CSMs shortens the service life of the road and increases the maintenance cost. How to improve the durability of CSMs has gradually become the focus of road workers. At present, scholars have carried out a lot of studies on the crack resistance, erosion resistance, frost resistance and fatigue resistance of CSMs [7-9]; and the influence of different factors, such as cement 
content, gradation and forming method, on the durability of CSMs has been investigated to effectively prolong the serviceable life of CSMs as road structural layer.

Under the current background of green development, how to promote the sustainable development of CSMs has gradually attracted the attention of scholars in various countries and regions. CSM is the main component of highway construction materials; its demand for cement and natural stones not only aggravates global carbon emissions, but also inevitably causes damage to the natural environment $[10,11]$. While large-scale infrastructure construction consumes natural resources and exacerbates carbon emissions, the treatment of waste materials formed by economic production activities worldwide is also a key area of environmental management [12-16]. The storage of waste materials not only occupies a lot of land, but also causes irreparable pollution to the surrounding environment. Promoting the recycling of waste materials is of great significance to improve environmental quality and accelerate the green transformation of economic and social development worldwide. At present, some regions have issued corresponding guidelines for the engineering application of waste materials, aiming to increase the recycling rate of waste materials $[1,17,18]$. Utilization of waste materials in highway and other infrastructure construction is undoubtedly an important measure to accelerate the consumption of waste materials and promote the green development of highway construction. Compared with concrete and pavement materials, CSMs have relatively lower strength requirements when applied in highway engineering. Different types of waste materials have been applied in CSMs to reduce the tremendous consumption of natural stone and cement in the construction of road infrastructure and reduce the stockpiles of waste materials.

At present, waste materials used in CSMs mainly include industrial by-products, mining waste, construction and demolition waste (CDW), municipal waste, waste rubber and waste fiber [19-24]. Different waste materials are used as aggregates, cementitious materials, fillers or admixtures in CSMs. It is worth noting that the introduction of waste materials can inevitably affect the durability of CSMs. Previous studies have mostly applied single-material waste in the preparation of CSMs, and evaluated the effect of waste materials on the mechanical properties and durability of CSMs $[2,22,23]$. The durability of CSMs is affected differently by the introduction mode and dosage of different waste materials. The introduction of waste rubber and waste fiber is conducive to improving the crack resistance and fatigue resistance of CSMs [25-28], while the application of recycled aggregate has a negative effect on the crack resistance and erosion resistance of CSMs [29]. Although a variety of waste materials have been tried to be utilized in CSMs, it is still facing great challenges to promote the sustainable development of CSMs based on the reuse of waste materials. Therefore, it is necessary to systematically investigate the introduction form, dosage range and effect on durability of different waste materials in CSMs, so as to promote the comprehensive utilization of waste materials in CSMs. In order to provide useful guidance for the sustainable development of highway CSMs, this review focuses on various influencing factors and improvement methods of the durability of CSMs. The impact of waste materials on the durability of CSMs has been systematically evaluated. The existing challenges for the sustainable development of CSMs are proposed. This review also aims to provide a reference for the large-scale recycling of various waste materials in CSMs.

\section{Durability of CSM}

Compared with asphalt mixture, using CSMs as backfill materials for road base or subgrade is very beneficial to control project costs. The stabilization of cementitious materials transforms the granular unbound structural layer to a stabilized structural layer that possesses considerable tensile strength, which improves the bearing capacity of the structural layer. Improving the durability of CSMs is an important aspect to ensure the serviceability of pavement within the design service life. The failure of CSM structure layer is closely related to material composition, traffic load and environmental impact. The main reasons of failure of CSMs include shrinkage crack development, erosion of fine materials 
under scouring, deformation under environmental effect and fatigue failure under traffic load. For a sustainable development, it is necessary to evaluate the failure mechanism and durability improvement measures of CSMs under different factors.

\subsection{Crack Resistance}

Cracking is one of the most common damages in CSMs. The cracking of CSMs mainly includes shrinkage cracking and fatigue cracking. There are micropores and shrinkage cracks in the CSM base at the initial molding stage [30,31]. Under the effect of traffic load and environment, micropores and shrinkage cracks develop gradually into macro fatigue cracks, and the mechanical properties decline gradually [32].

The factors affecting the crack resistance of CSM include the material content, gradation, molding method and curing conditions. The material content mainly includes cement content, moisture content and content of filler with particle size less than $0.075 \mathrm{~mm}$. In the early stage of CSM base design, most of the engineering required to increase the cement content to pursue high mechanical strength, which made the road base had high stiffness but poor toughness. It was prone to tensile cracks and shrinkage cracks at the bottom surface of the structural layer. Liao et al. [33] compared the mechanical properties and crack resistance of cement-stabilized aggregate (CSA) with different cement content. With the increase of cement content, the mechanical properties of CSM show an increasing trend, and there is an optimal cement content to minimize the dry-shrinkage strain (Figure 1). When the moisture content of CSM is high, the moisture among the particles evaporates in the curing stage, and then dry-shrinkage cracks are produced. The high content of filler with particle size less than $0.075 \mathrm{~mm}$ in CSMs is not conducive to the crack resistance of the mixture [6]. The content of filler with particle size less than $0.075 \mathrm{~mm}$ in CSM is recommended to be $2-5 \%$ for the expressway base according to crack resistance requirements.

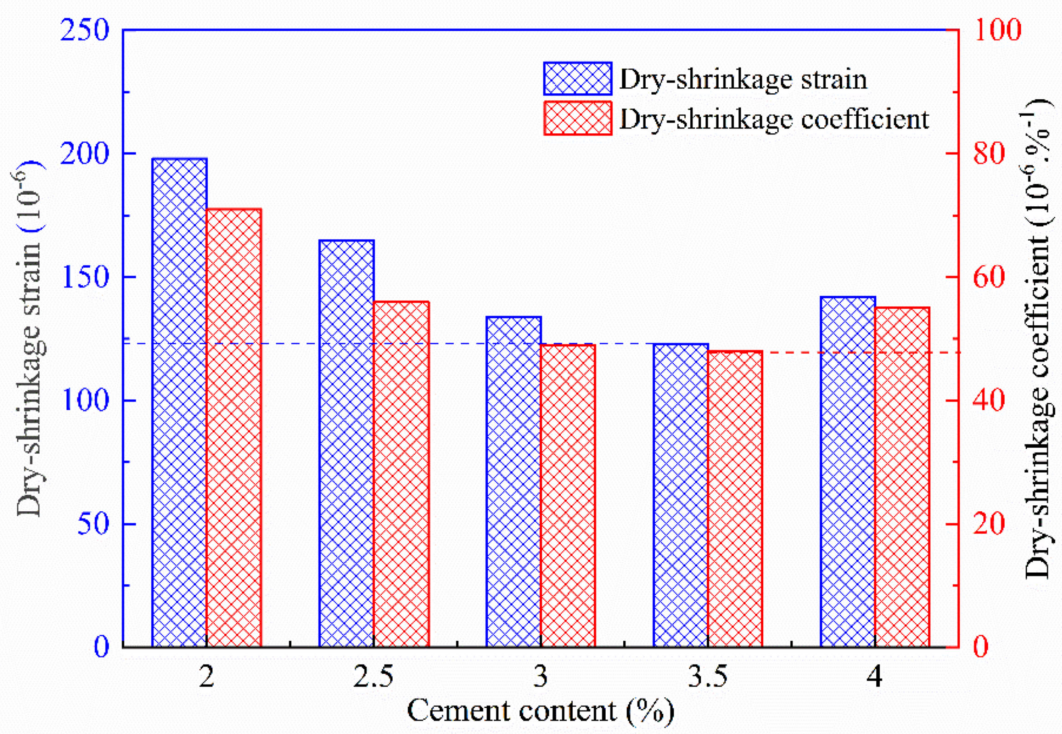

Figure 1. Dry-shrinkage strain and coefficient of CSA [33].

Some studies [34-37] had been conducted to improve the crack resistance of CSM by adding materials. The added materials include rubber particles, rubber powder, metakaolin, fiber, desulfurization gypsum and emulsified asphalt. Lv et al. [34] prepared the rubberCSA by replacing the same size aggregate with $2.36-4.75 \mathrm{~mm}$ rubber particles. As shown in Figure 2, rubber particles enhance the flexural tensile deformation of CSA. When the content of rubber particles is $76 \%$, the maximum bending strain of rubber-CSA can reach 3.79 times of that of traditional CSA. The incorporation of rubber powder is beneficial to improve the dry shrinkage and thermal shrinkage of CSMs, and it slows down the shrinkage cracking 
of base course [38]. However, the mechanical properties of CSMs decrease obviously when the rubber powder content exceeds $1.5 \%$. The addition of metakaolin can improve the engineering performance of CSMs, reduce the dry-shrinkage strain and shorten the setting time [36]. At present, different types of fibers, including polyester fiber, polypropylene fiber, basalt fiber and nylon fiber, are used to enhance the crack resistance of CSMs. Liu et al. [39] found that the average dry-shrinkage coefficient of CSM first increases and then decreases with the increase of polyester fiber diameter, while the temperature-shrinkage coefficient increases. The more dispersed fiber filaments are beneficial to enhance the deformation resistance of CSM.

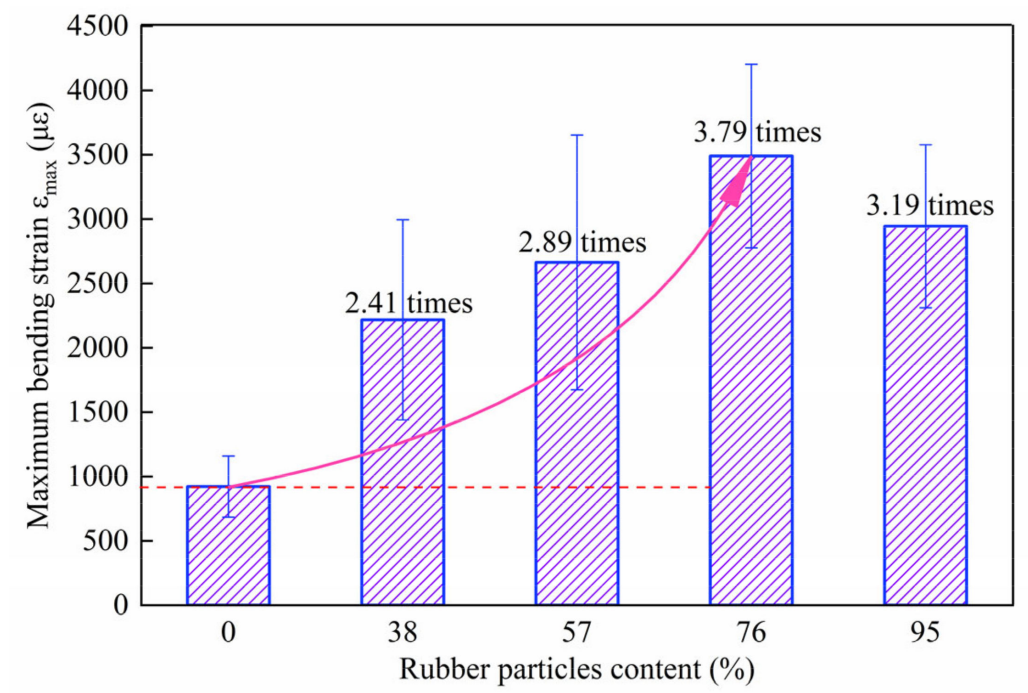

Figure 2. Test results of maximum flexural tensile strain of CSM with different rubber particle content [34].

In addition, adjusting the gravel gradation is conducive to improve the crack resistance of CSA. The strength, rigidity and anti-cracking deformation of CSA with skeleton dense structure are better than those with suspended dense structure. The study [40] also concluded that the CSA with skeleton dense structure had excellent crack resistance. Reasonable molding method is very important to improve the crack resistance of CSM base. Vibration compaction (VC) is recommended in China's specification Technical guidelines for construction of highway roadbases (JTG/T F20-2015). The VC method can reduce the cement content in the design of material composition. Its action mode on CSM base is closer to that of actual construction, and it can ensure the Unconfined compressive strength (UCS) of CSM to meet the specification requirements [41]. The standard heavy proctor compaction (SHPC) is still the main method in the selection of construction parameters in existing engineering. Previous studies [42,43] indicated that the optimum moisture content obtained by SHPC was relatively large, which was also an important reason for the frequent occurrence of dry-shrinkage cracks in the CSM base. The optimum moisture content of the samples formed by gyratory compaction (GC) and VC is obviously lower than that of the heavy compacted samples $[44,45]$. The structure of samples formed by GC and VC is stronger, which effectively controls the drying-shrinkage cracking caused by water loss in the process of maintenance. This phenomenon is more obvious for cement-stabilized recycled aggregate (CSRA) [43].

There are differences in the moving form of aggregate and the filling effect of cementing material in CSAs between VC and static compaction (SC) [46]. The internal aggregate and cementitious materials of the CSA is arranged and distributed better under the VC, and the structure is more stable under the vibration force. For CSAs formed under SC, the distribution of cementitious materials is not uniform during the loading process. In addition, stress concentration is easily generated at the contact point of coarse aggregate, 
which leads to aggregate crushing, and the compactness of formed samples is also low [46]. It indicates that the CSA formed by VC has better crack resistance, and this phenomenon is more obvious in the CSM with pre-cracking treatment.

The shrinkage stress is produced by the change of humidity during the curing period, which is also one of the important reasons for the cracking of CSM base and the reflection crack of surface layer. Timely moisturizing and curing of CSM base can effectively alleviate the occurrence of drying-shrinkage cracks [6]. The cracks of CSM base mainly occur in the first three days after construction, and the cracks are mainly dry-shrinkage cracks. The dry-shrinkage cracks basically stopped developing after 30 days of construction. Therefore, it is extremely important to do sprinkling curing well in the early stage to reduce the dry-shrinkage cracks [47]. In addition, some scholars [46,48,49] suggested that pre-cracking treatment should be adopted to reduce the cracking damage of CSM base. It means the vibration roller should be used for pre-splitting treatment in the early stage of curing. The microcracks produced by pre-cracking treatment have good ability to disperse stress, absorb early shrinkage stress and prevent large shrinkage stress cracking [48]. Duan et al. [46] concluded that the greater the pre-cracking degree, the smaller the dry-shrinkage strain of the CSM, but the overall crack resistance first increased and then decreased. As shown in Figure 3, the CSMs have the best pre-cracking time and pre-cracking degree, and the samples formed by VC have better crack resistance after pre-cracking treatment.
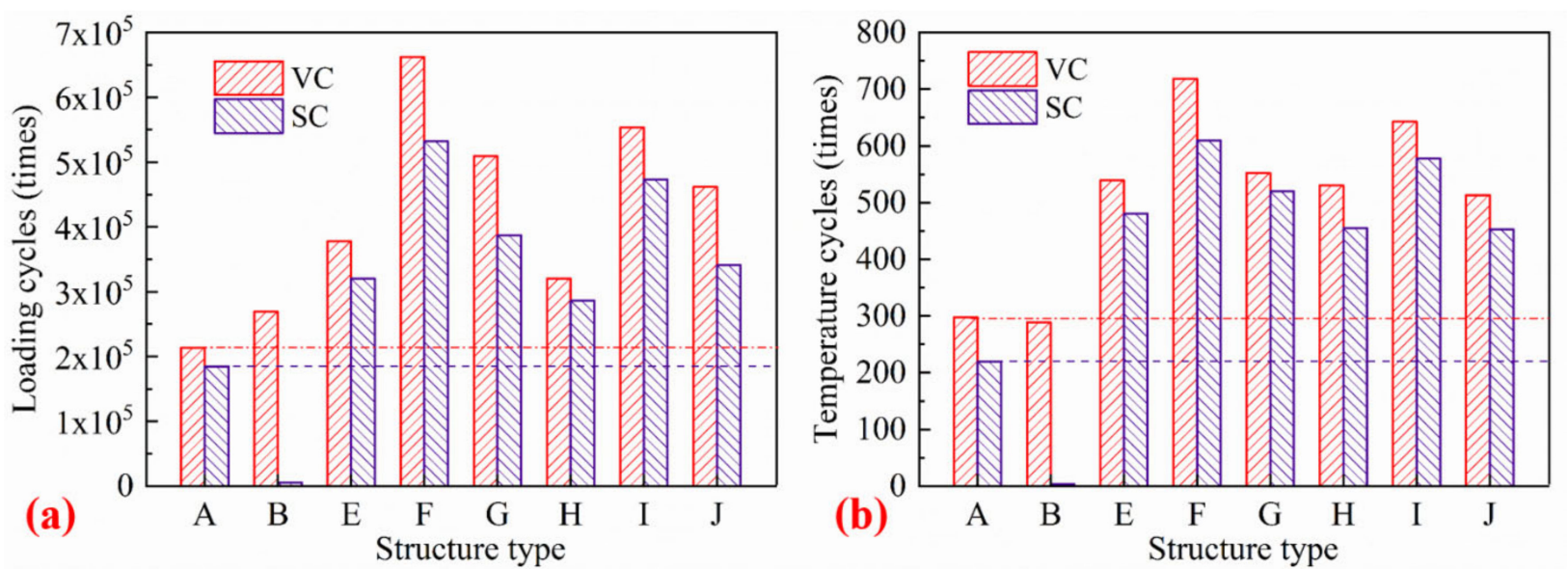

\begin{tabular}{|l|c|c|c|c|c|c|c|c|}
\hline No. & A & B & E & F & G & H & I & J \\
\hline Pre-cracking time (d) & $\mathbf{0}$ & $\mathbf{1}$ & $\mathbf{2}$ & $\mathbf{2}$ & $\mathbf{2}$ & $\mathbf{3}$ & $\mathbf{3}$ & $\mathbf{3}$ \\
\hline Pre-cracking degree of CSM (\%) & $\mathbf{0}$ & $\mathbf{2 0}$ & $\mathbf{2 0}$ & $\mathbf{3 0}$ & $\mathbf{4 0}$ & $\mathbf{2 0}$ & $\mathbf{3 0}$ & $\mathbf{4 0}$ \\
\hline
\end{tabular}

Figure 3. Cracks resistance of CSM with different pre-cracking degree: (a) loading cycles and (b) temperature cycles [46].

\subsection{Anti-Erosion Performance}

The main reason for the formation of erosion is the separation of fine materials which are not closely connected on the surface of CSM base under the action of hydrodynamic pressure pumping $[6,50]$. The erosion damage degree of CSM base is related to the crack formation mode [51]. The erosion at the low thermal shrinkage crack of asphalt layer surface mainly occurs between the bottom surface of the asphalt course and the top surface of the CSM base. The erosion of surface cracking caused by reflection cracks of CSM base is the most serious, and the dynamic water erosion occurs at the junction of surface course and base course and the upper surface of subbase. The microcracks formed by construction and other factors can cause a small amount of water enter into the CSM base. With the gradual saturation of the water content of the CSM base, the erosion effect is more obvious, which leads to the pit and groove in the surface layer. 
It is very important to determine the accurate scour conditions for evaluating the anti-erosion performance of CSMs. At present, the test methods used to evaluate the antierosion performance of CSMs include revolving erosion-corrosion test, rotational shear test and scouring test based on shaking table [52]. Hao et al. [7] recommended that the erosion rate within 5 min should be used as the evaluation index of anti-erosion performance of CSMs. Sha and $\mathrm{Hu}$ [53] reported that the scouring amount of cement-stabilized soil (CSS) increased linearly with the increase of scouring time, while the scouring amount of CSA gradually decreased in the later stage. It is recommended that the force of $0.5 \mathrm{MPa}$, the action frequency of $10 \mathrm{~Hz}$ and the action time of $30 \mathrm{~min}$ were taken as the standard scouring conditions. Zhu et al. [52] analyzed the relationship among scouring depth, scouring times, hydrodynamic pressure and UCS of CSMs. When the hydrodynamic pressure is significantly higher than the UCS of CSMs, the hydrodynamic scouring damage is more obvious. Therefore, CSMs used in heavy traffic conditions should have good anti-scouring performance.

When the stabilized materials are different, the erosion mechanism of CSM is different. From the aspect of material composition, the main factor affecting the anti-erosion performance of CSS is cement content. The greater the spatial distribution density of cement mortar skeleton net, the stronger the anti-erosion performance of CSS is. The factors that affect the anti-erosion performance of CSA include the combination of fine materials, coarse aggregate gradation and water permeability [51,54]. The anti-erosion performance depends on cement content, stability degree of fine particles and skeleton effect of coarse particles. The anti-erosion ability is affected by the condition of fine particles at the initial stage and by the condition of coarse particles in the later stage of scouring. Sha and $\mathrm{Hu}$ [40] observed that the gradation type could affect the anti-erosion performance of CSA, and the CSA with skeleton void structure had the best erosion resistance. The aggregate cementation state of CSA with different gradation is different. The aggregate specific surface area of CSAs with high fine particle content is large, the limited cementitious materials in CSA are difficult to ensure the cementation of all fine aggregates. Especially when the surface water is immersed in the CSA base, the scouring effect of hydrodynamic pressure on fine particles is more obvious with the further weakening of bonding effect. Therefore, more cement slurry is needed to bond the fine aggregate under the action of scouring. The anti-erosion test results of different types of CSM are shown in Figure 4 [51]. When the content of fine particle material is high, it is necessary to increase the amount of cement to improve the anti-erosion performance [40,51]. For CSMs, there is a critical cement content below which scouring increases very rapidly. In addition, increasing the content of aggregate with particle size greater than $16 \mathrm{~mm}$ is conducive to improve the intercalation effect of aggregate, so as to obtain better erosion resistance [54].

The erosion process of CSM base is actually a fatigue process in which the cracks in the CSM base continue to expand and the fine materials continue to peel off under the action of dynamic water and load. Adding fiber into CSM can effectively reduce the impact effect, improve the cohesion of materials, reduce the stress sensitivity and reduce the propagation rate of fatigue crack under scour and load. He et al. [27] found that the erosion resistance of CSM reinforced with the polypropylene fiber was increased by more than $30 \%$. Optimizing the mixing process is also conducive to improve the anti-scour performance of CSMs. Chen et al. [55] believed that using vibration mixing technology mixed CSMs more evenly, which is conducive to improving the dispersion of cement and the adhesion to fine aggregates. In addition, the setting of waterproof adhesive layer is conducive to optimize the scouring environment of CSM base and reducing the scouring of water on CSM base [56]. In general, the dynamic water erosion of CSM can be reduced by reducing the fine particle content, increasing the degree of bonding and porosity. CSA base structure is recommended for heavy traffic road sections with high anti-erosion requirements or abundant rainfall. However, it is necessary to control the cement content properly and reduce the use of recycled aggregates (RAs) [57]. 

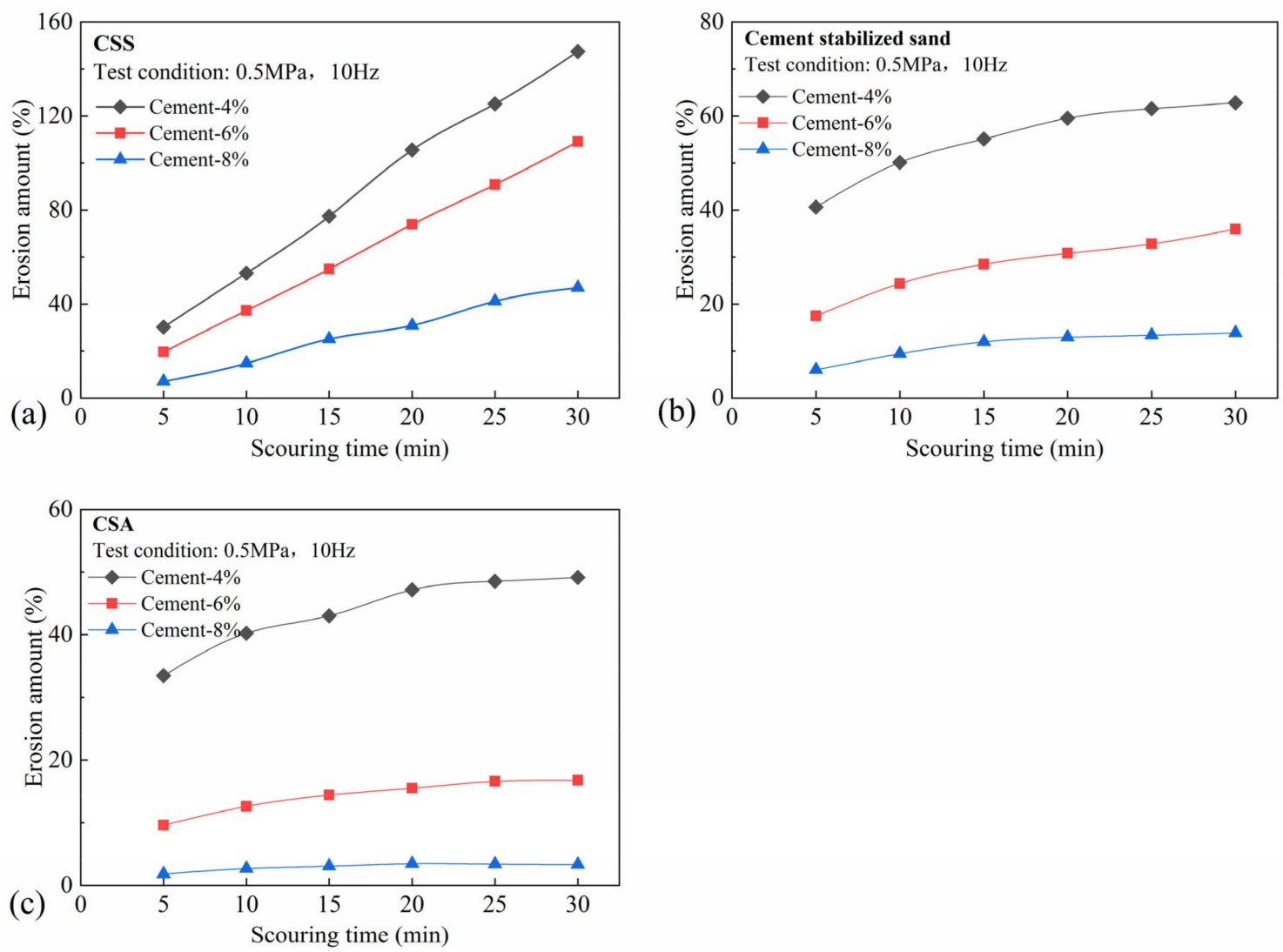

Figure 4. Test results of erosion resistance of different types of CSMs: (a) CSS, (b) cement-stabilized sand, and (c) CSA [51].

\subsection{Frost Resistance}

The frost resistance of CSM base is relatively good if the asphalt surface is in good condition. When penetration cracks are formed in the base layer and the surface layer, the water in pavement surface is easy to immerse in the CSM base. The moisture freezes and expands when the temperature is lower than $0{ }^{\circ} \mathrm{C}$, which affects the durability of CSM base. In the seasonal frozen area or saline soil area, the damage of CSM base is more serious due to freeze-thaw cycles. With the increase of freeze-thaw cycles, the internal damage degree of CSM increases, and its bending tensile strength decreases sharply [58]. The immersion of water is the inducement to accelerate the frost heaving damage of CSMs in cold regions [8,59]. When water is immersed into the micropores and microcracks in the CSM, with the decrease of temperature, water is transformed into ice and the volume expansion occurs. The ice crystal produces stress concentration in the microcracks and micropores, which leads to the attenuation of the mechanical properties of the CSM.

The frost resistance of CSMs is related to its internal void structure, water absorption and strength of aggregate. The frost resistance of CSM prepared with RA is obviously inferior. Under the action of freeze-thaw, the initial microcracks and pores in the CSM sample gradually develop into interconnected macrocracks, and the growth trend of damage variables increases significantly in the middle and later stage of freeze-thaw cycles, resulting in large-area peeling of aggregate for CSM. Xu et al. [59] evaluated the effect of freeze-thaw cycles on the pore structure and mechanical properties of porous CSA. With the increase of freeze-thaw cycles, the UCS and indirect flexural strength of porous CSA gradually decreased, and the mass loss increased. The freeze-thaw cycles lead to cement and fine aggregate falling from CSA samples. The water-immersion-frozen/freeze-thaw cycle has the greatest damage to the performance of porous CSA. When porous CSA is applied, the water-immersion-freeze-thaw cycle caused by interlayer water accumulation can be reduced by increasing the permeability of substructure. Wang et al. [60] concluded 
that the damage degree of CSA could reach $15.7 \%$ after 20 freeze-thaw cycles, and the flexural tensile strength decreased by about $52 \%$ compared with the unfrozen samples. The variation of fatigue life of CSAs after different freeze-thaw cycles is shown in Figure 5 [8]. At the initial stage of freeze-thaw cycles, the fatigue life of CSAs decreases seriously. The deformation of CSMs under freeze-thaw cycles makes it easy to form microcracks, which weakens the frost resistance of CSMs. In addition, the high content of fine aggregate has an adverse impact on the frost resistance of CSMs. Fine aggregate has strong water absorption and can accelerate the development of microcracks in CSMs at low temperature.

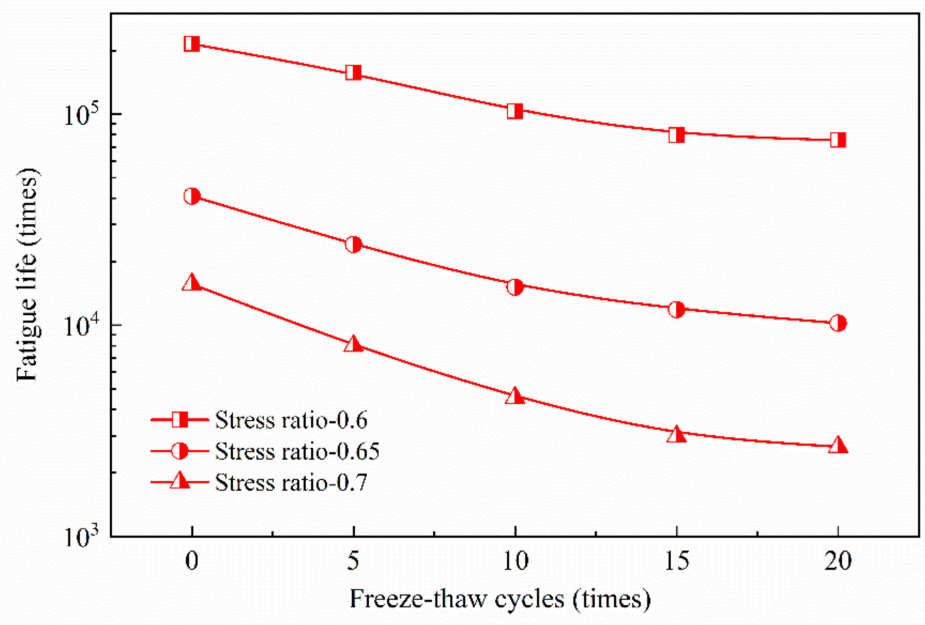

Figure 5. Fatigue life of CSM under different freeze-thaw cycles [8].

Reducing the influence of water on CSMs is the key to improve the frost resistance of CSMs. Improving the frost resistance of CSMs can be optimized from its own structure and material composition, such as reducing the void ratio, increasing the cement content appropriately and adding toughening auxiliary materials [60-62]. Additional materials such as fly ash (FA), rubber particles, emulsified asphalt and fiber are used to enhance the toughness and deformation resistance, so as to improve the frost resistance of CSMs [63,64]. In addition, the frost resistance of CSMs can be increased by increasing the cement content and curing time. The previous study [65] indicated that the addition of emulsified asphalt could effectively inhibit the thermal shrinkage of CSA. With the increase of emulsified asphalt content, the temperature-shrinkage strain and average temperature-shrinkage coefficient of the specimens were gradually decreasing, but the content of emulsified asphalt should be controlled within 3\%. In addition, the frost resistance of CSA base course can be improved from the aspects of optimizing the structural form, reasonably controlling the curing conditions and setting waterproof structural layer $[59,66]$.

\subsection{Fatigue Resistance}

The fatigue resistance of CSM is an important foundation to ensure the structural performance of the surface course of asphalt pavement, and the improvement of fatigue performance is also a key technical difficulty for the asphalt pavement with CSM base to become a permanent pavement [67]. CSM is a kind of material composed of multicomponent and multi-phase. The CSM with different material composition, structural type and environmental conditions has different fatigue characteristics. The fatigue life of CSM base has a strong correlation with the tensile state of the bottom surface of the structure [68]. In addition, the tensile strength of CSM is the main factor affecting the fatigue life, and properly improving the bending tensile strength can make up for the defect of rapid fatigue life decay [69,70]. When the CSM structural layer is continuously loaded, the bond among the aggregates or between the binder and aggregate loses and forms microcracks. These microcracks gradually expand under repeated loading and eventually lead to the fatigue failure of the CSM mixture $[69,71]$. 
The fatigue characteristics of CSM have been mainly evaluated by a cyclic four point bending tests $[69,70,72]$. The establishment of fatigue failure model is an important link to study the fatigue resistance of CSMs. Scholars hope to establish an effective fatigue failure model of CSM to accurately evaluate the evolution of fatigue failure. At present, the fatigue failure models of CSMs can be divided into two groups: strain-based fatigue model and stress-based fatigue model [69,73]. In strain-based failure models, the fatigue life is defined as a function of initial tensile strain at the bottom surface of CSM layer or the ratio of applied tensile strain to breaking strain [73], in which the failure model based on initial tensile strain is preferred. Strain based failure models established by Jameson et al. [74] and Austroads [75] selects elastic modulus as independent parameter. However, Biswal et al. [73] observed that inclusion of elastic modulus in the fatigue model results in improvement of fatigue relationships very marginally. In addition, the strain failure models established by American and French scholars [76,77] also do not consider the elastic modulus as an important parameter of fatigue failure evaluation. The flexural tensile failure strain is recommended as an independent parameter in strain-based failure model. The relationship between fatigue life and initial strain was found to be linear in a semilog plot [73].

As one of the main forms of failure model of CSMs, the establishment of stress-based failure model is also very important to understand the fatigue failure of CSMs. In stressbased fatigue models, fatigue life of a CSM layer is a function of stress ratio [69]. The existing studies $[23,70,78]$ on stress-based failure models mostly considered that the fatigue failure of CSMs follows Weibull distribution, and it is recommended to use the Weibull distribution model with two parameters to fit the fatigue failure of CSMs. The construction of stress-based fatigue equation mainly includes single logarithmic fatigue equation and double logarithmic fatigue equation $[69,72,79]$. The stress-based fatigue-failure models of different CSMs are compared in Figure 6.
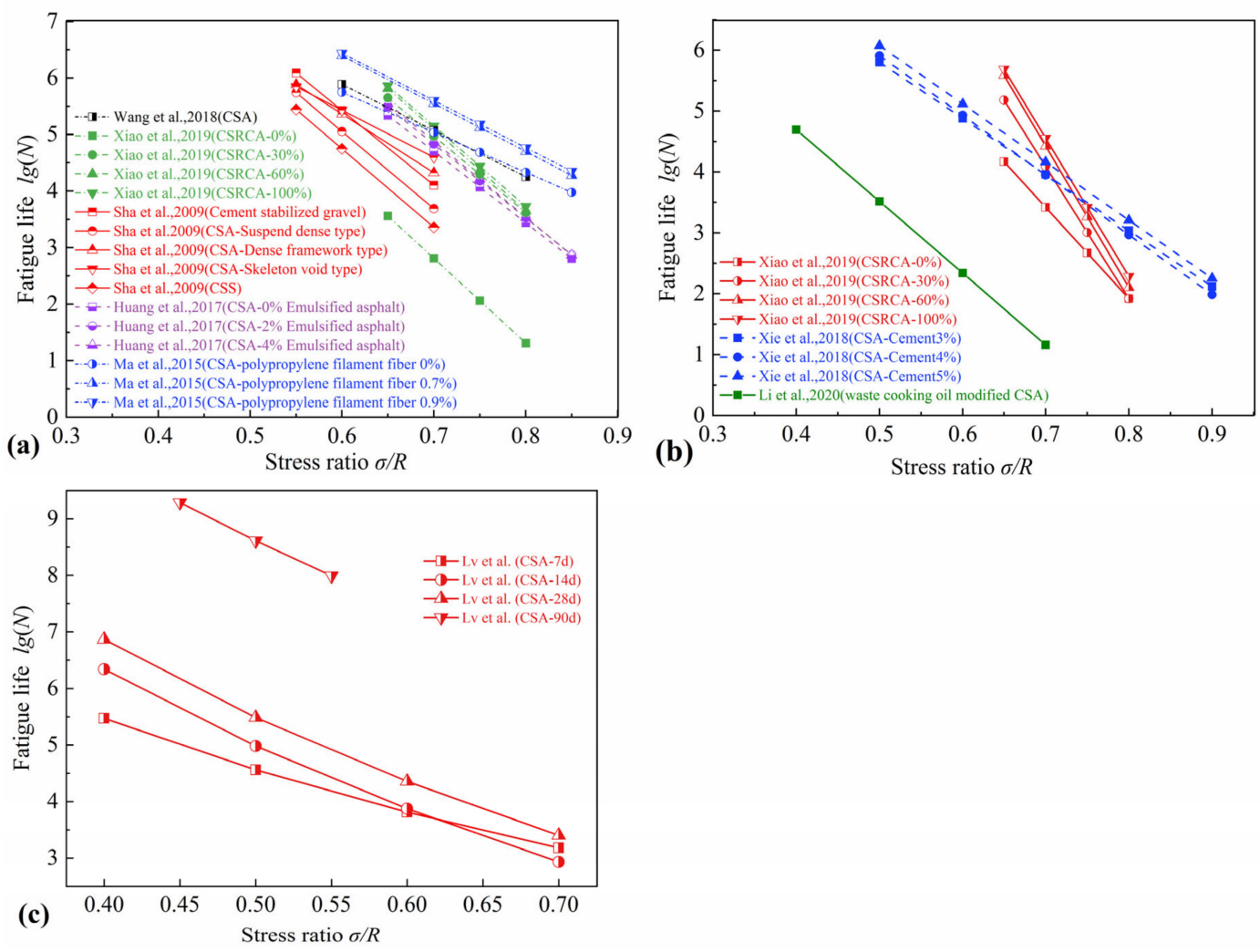

Figure 6. Stress-based fatigue failure models of different CSMs: (a) failure models of CSMs with 50\% guarantee rate $[23,69,70,80,81]$, (b) failure models of CSMs with 95\% guarantee rate $[23,79,82]$ and (c) failure models of CSMs in different curing period [72]. 
As shown in Figure 6a,b, the fatigue characteristics of different CSMs are obviously different, but the fatigue life and stress ratio show a linear relationship in the semi logarithmic coordinates. With the increase of stress ratio, the fatigue life of CSMs decreases obviously. At low stress level, CSMs have long fatigue life. The applicable traffic load conditions can be determined according to the stress-based failure model of different CSMs. The fatigue resistance of CSM was improved by adjusting the structure type, cement content, molding method and admixture in previous studies [23,69,70,82]. The introduction of emulsified asphalt, RAs and waste cooking oils can improve the fatigue characteristics of CSMs, but these admixtures have an adverse effect on the flexural tensile strength $[23,70,79]$. The introduction of cement and fiber can increase the flexural tensile strength and fatigue life [81,82]. There is little difference in the failure equation of CSMs under different guarantee rates. The structure type has a great influence on the fatigue life, and the fatigue resistance of CSM with skeleton dense structure is better than that with suspended dense structure [9].

For the CSM with the same gradation, properly increasing cement content can enhance its fatigue resistance to repeated load [5]. The incorporation of admixtures such as fiber [81] and rubber [21] can improve the fatigue resistance of CSM. Ma et al. [81] revealed that low content of polypropylene filament fiber could increase the fatigue life of CSM by 1.0-4.2 times. Figure 7 shows the structural comparison of CSM before and after adding fiber. The existence of fiber improves the internal structure density of CSM and forms strong anchoring force, which is conducive to improving the strength and fatigue performance of CSM. In addition, adding rubber particles into CSM with low cement content can improve its toughness, and rubber replacement can delay the failure rate of CSM [21].
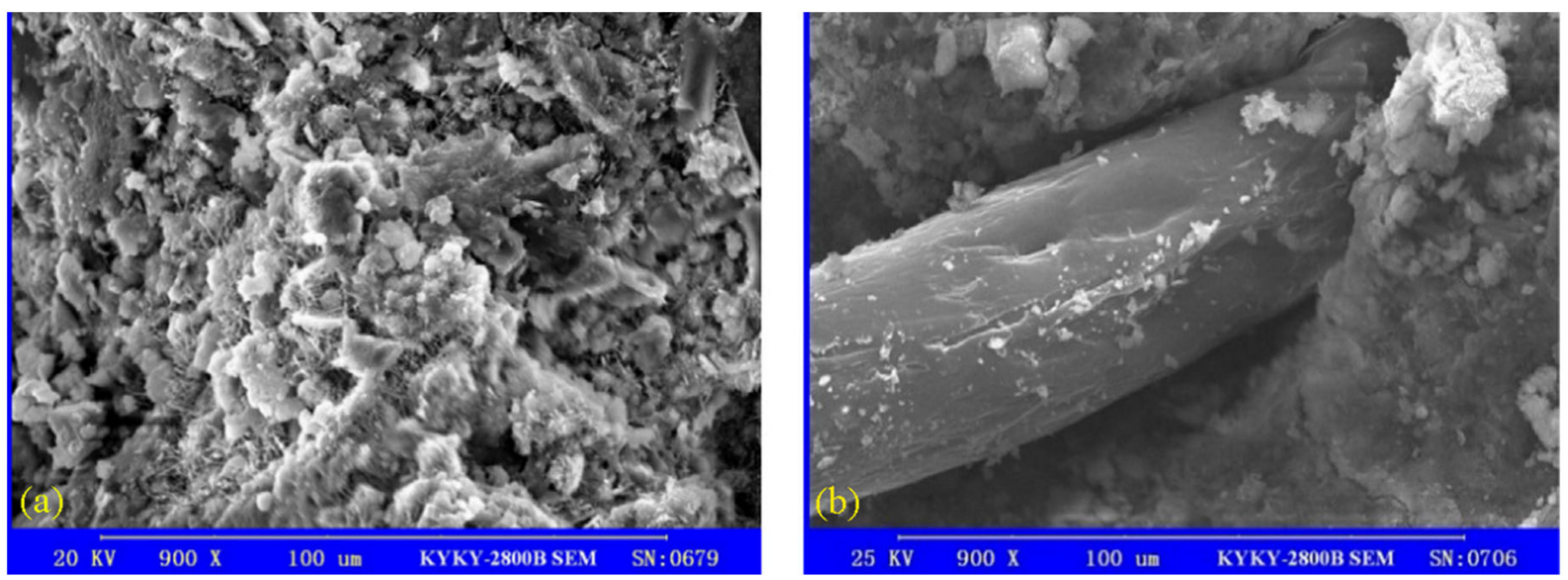

Figure 7. Micro-structure of CSA: (a) CSA and (b) CSA with fiber [81].

As shown in Figure 6c, the fatigue life of CSMs increases significantly with the increase of curing period [72]. Precise control during the curing period is important to improve the fatigue resistance of CSM. Lv et al. [71] compared the effects of curing time and loading rate on the fatigue life of CSM. The damage of short-term curing CSM is more serious under load. Increasing the curing time is beneficial to improve the fatigue resistance of CSM. According to the modulus attenuation law of CSM, the fatigue process is divided into initial stage, stable stage and failure stage. Therefore, it is of positive significance to appropriately extend the curing period of CSMs to improve their fatigue life when the construction period is allowed. Wang et al. [80] analyzed the influence of overloading by construction vehicles on cracking mechanism of CSM base. The results showed that the damage caused by the construction machinery to CSM base during construction was far greater than the damage after reaching the design strength. According to the previous studies $[5,72,81]$, strengthening the adhesion between aggregate and cementing material is the key point to improve the fatigue resistance of CSM. It is beneficial to enhance the 
fatigue resistance of CSM by adopting reasonable gradation type, properly increasing cement content and improving the toughness of CSM.

\section{Utilization of Waste Materials in CSMs}

\subsection{Sources of Waste Materials}

With the continuous implementation of the concept of green development, more and more waste materials are tried to be utilized in CSM base and subgrade construction. The application of waste materials in CSM base and subgrade has become an important direction in road construction. Waste materials utilized in CSMs include wastes generated in mining and industrial production $[13,22,30,83]$, CDWs $[57,84]$, municipal waste $[2,79,85]$. In addition, solid wastes such as waste rubbers and waste fibers are also applied in CSM base $[64,86,87]$. When waste materials are used in the preparation of CSMs, comprehensive considerations are generally made in various aspects, such as material properties, engineering requirements and technical feasibility, so as to improve the application effect and resource application level of waste materials. The sources and forms of waste materials are quite different, and their influence on the performance of CSMs is different. Figure 8 shows waste materials mainly applied in CSMs.

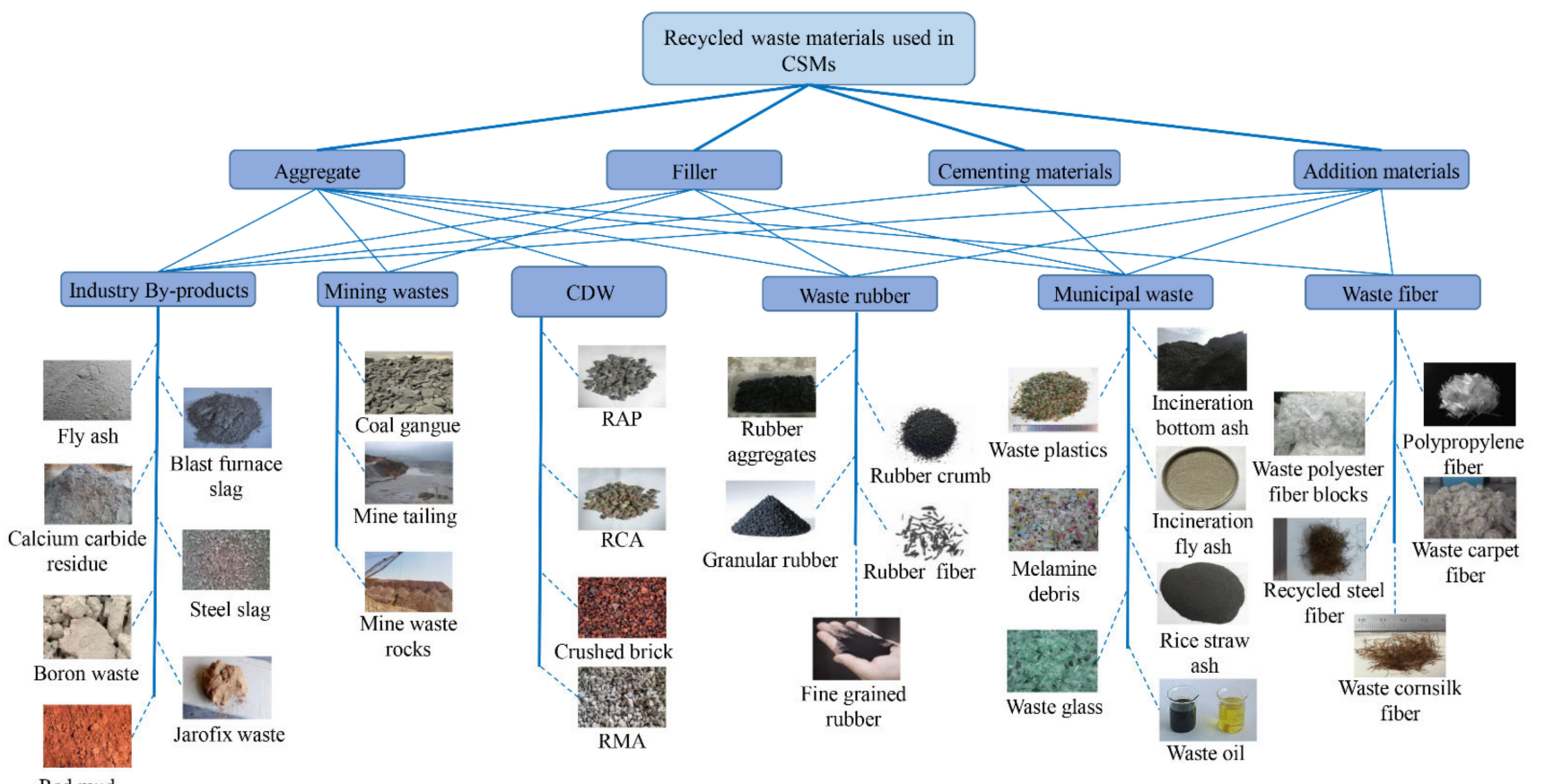

Figure 8. Waste materials used in CSM.

Industrial by-products and mining wastes are the two most serious types of solid wastes in terms of storage volume and land occupation [88,89]. At present, the utilization of industrial and mining waste residue in large-scale infrastructure such as highways is one of the main ways to accelerate the consumption of waste resources. At present, industrial and mining wastes used in highway engineering construction include FA, blast furnace slag, steel slag, carbide residue, coal gangue, mine tailing, waste rock and so on [89-93].

CDWs are also one of the main solid wastes used for CSMs. It mainly comes from production activities such as building demolition or old road renovation. There are many kinds of CDWs, which can be divided into recycled asphalt pavement (RAP), recycled cement base (RCB), recycled concrete aggregate (RCA), crushed brick $(\mathrm{CB})$ and recycled mixed aggregate (RMA) [23,84,94-97]. In addition, municipal waste, waste rubber and waste fiber are also applied in the preparation of CSMs. At present, the waste fibers used in CSMs include waste polyester fiber fabric blocks, polypropylene fiber bags, ny- 
lon fibers, waste carpet fibers, steel fiber, waste corn-silk fibers and waste-tire textile fibers $[28,86,87,98-100]$. The application of different waste materials in CSMs cannot only reduce the environmental pollution caused by the disposal or storage of waste materials, but it can also promote the green and sustainable development of road CSMs.

\subsection{Incorporation Forms of Waste Materials}

Due to the different sources and forms of wastes, the influence of waste resources on the durability of CSM is also different [101]. The introduction of different waste materials in CSMs is related to their particle size, shape and activity. As shown in Figure 8, the incorporation forms of industrial and mining wastes in CSMs mainly include aggregate, filler and cementing material. Industrial by-products and mining waste with high strength are generally used as coarse aggregate [22,93]. Activated coal gangue, FA, blast furnace slag and sintered limestone powder are ground to partially replace cementitious materials [83,102]. FA with high activity and waste rock powder are used as filler [103]. CDWs are mainly used to partially replace the natural aggregate.

The treatment of municipal waste is one of the major problems facing big cities. There are many kinds of municipal waste, and they are widely applied in CSM. Part of the directly recyclable municipal waste is used as aggregate due to its good engineering characteristics. As a kind of municipal waste, the accounts of waste glass is about $6 \%$ of municipal waste. It is mainly used as fine aggregate in CSMs $[85,104]$. Waste cooking oil is used in CSMs to optimize the interface among cement and aggregate $[79,105]$. In addition to the municipal waste which can be directly recycled, most of the municipal waste is treated by incineration $[2,20,106]$, which can effectively reduce the land occupation of urban municipal waste and generate electricity. The bottom ash (BA) and FA formed by municipal solid waste incineration (MSWI) have also been tried to be used as fine aggregate or cementing material in CSMs $[2,20]$. Waste rubber is mainly divided into particle, powder and fiber according to its processing method [107-109]. Waste rubber is mainly used as fine aggregate, filler and admixture of CSMs. The particle size of waste rubber is small, and its incorporation forms is shown in Table 1. Waste fiber is mainly used as admixture to improve the durability of CSMs.

Table 1. Incorporation forms of waste rubber in CSM.

\begin{tabular}{|c|c|c|c|c|c|c|c|}
\hline Types & Replacement level & Size & Cement Content (\%) & Moisture Content (\%) & Stabilized Material & Molding Method & References \\
\hline Particle & $30 \%$ by volume of $6 \mathrm{~mm}$ particles & $6 \mathrm{~mm}$ & $3,5,7$ & $4.5,4.6,4.7$ & Aggregate & $\mathrm{VC}$ & [21] \\
\hline Particle & $\begin{array}{l}2 \%, 3 \%, 4 \% \text { and } 5 \% \text { by volume of } \\
2.36-4.75 \mathrm{~mm} \text { particles }\end{array}$ & $2.36-4.75 \mathrm{~mm}$ & 4.5 & $5.7,5.4,5.2,5.1$ & Aggregate & vC & [34] \\
\hline Particle & $2.5 \%, 5 \%, 7.5 \%$ and $10 \%$ by weight of clay & $0.8-2 \mathrm{~mm}$ & $0,3,6$ & - & Clay & SHPC & {$[110,111]$} \\
\hline Particle & $0 \%, 5 \%, 10 \%$ and $15 \%$ by dry mass of the kaolin & $2-5 \mathrm{~mm}$ & $0,2,4$ & - & Kaolin & SHPC & {$[108]$} \\
\hline Particle & $30 \%$ by volume of $6 \mathrm{~mm}$ particles & $6 \mathrm{~mm}$ & $3,5,7$ & $4.5,4.6,4.7$ & Aggregate & VC & [112] \\
\hline Particle & $15 \%, 30 \%$ and $45 \%$ by volume of $6 \mathrm{~mm}$ particles & $6 \mathrm{~mm}$ & 5 & 4.6 & Aggregate & $\mathrm{VC}$ & {$[25,26]$} \\
\hline Particle & $0 \%, 1 \%, 2 \%, 3 \%$ and $4 \%$ by dry weights of soil & $\begin{array}{l}\text { Length 3-6 } \mathrm{mm} \text {, thickness } \\
\text { less than } 2 \mathrm{~mm}\end{array}$ & $0,2,4$ & 24 & Soil & SC & [113] \\
\hline Powder & $0 \%, 0.5 \%, 1 \%, 1.5 \%, 2 \%, 2.5 \%$ and $3 \%$ of total mass & 40 mesh & $4,5,6$ & - & Aggregate & SC & [38] \\
\hline Powder & $0.5 \%, 1 \%$ and $1.5 \%$ by volume of aggregate & 80 mesh & - & - & Aggregate & VC and SC & [109] \\
\hline Powder & $0 \%, 5 \%, 10 \%, 15 \%$ and $20 \%$ by weight of cement & 30-40 mesh, 60-80 mesh & $7,15,20,25$ & 20 & Soil & SHPC & [114] \\
\hline Powder & $1.0 \%, 1.5 \%$ and $2.0 \%$ by volume of fine aggregate & 40 mesh, 60 mesh, 80 mesh & 4 & 4.5 & Aggregate & SC & [115] \\
\hline $\begin{array}{l}\text { Powder and } \\
\text { fibers }\end{array}$ & $\begin{array}{c}\begin{array}{c}10 \%, 20 \%, 30 \%, 40 \%, 80 \% \text { and } 100 \% \text { by volume of } \\
\text { dry soil }\end{array}\end{array}$ & $<1 \mathrm{~mm}$ & 10 & 50 & Soil & SHPC & [116] \\
\hline Fibers & $2.5 \%, 5 \%, 7.5 \%$ and $10 \%$ by weight of clay & $\begin{array}{c}\text { Width } 2-3 \mathrm{~mm} \text {, length } \\
15 \mathrm{~mm}\end{array}$ & $0,3,6$ & - & Clay & SHPC & [107] \\
\hline Fibers & $5 \%, 10 \%$ and $15 \%$ by weight of soil & $\begin{array}{l}\text { Length } 10-20 \mathrm{~mm}, \\
\text { thickness } 1.5-2.5 \mathrm{~mm}\end{array}$ & $5,10,15$ & 16.4 & Soil & SHPC & [117] \\
\hline Fibers & $0 \%, 0.5 \%, 1 \%$ and $2 \%$ by weight of clay & $3-10 \mathrm{~mm}$ & $5,7.5,10$ & 13 & Clay & SHPC & [118] \\
\hline
\end{tabular}

\section{The effect of Various Waste Materials on Durability of CSMs}

\subsection{Industrial and Mining Waste}

When industrial and mining wastes are used to replace aggregate or soil in CSMs, the source, strength, particle size and gradation of waste materials have a significant impact on the durability of CSMs. Table 2 shows the influence of different industrial and mining wastes on the durability of CSMs. Previous studies [22,119] indicated that cement-stabilized coal gangue had high flexural tensile strength, excellent frost resistance and low thermal shrinkage. The performance of cement-stabilized coal gangue is greatly affected by the source of coal gangue. For the industrial and mining waste slag with 
high crushing value, it is recommended to replace it as fine aggregate in CSA. Using steel slag to partially replace aggregate can reduce dry-shrinkage strain, but has little effect on temperature-shrinkage strain $[30,93]$. The incorporation of waste slag, such as coal gangue, steel slag and crushed, stone waste can improve the crack resistance and frost resistance of CSMs, which is mainly related to the particle size distribution and surface morphology of waste slag [88,93,119-121]. Similar to traditional CSA, the content of cement in cement-stabilized waste slag has an obvious effect on crack resistance. It is recommended that the cement content of cement-stabilized steel slag should not exceed $4 \%$ to effectively reduce the occurrence of drying-shrinkage cracks [30]. In addition, boron waste and jarofix is also applied in CSMs. The addition of boron waste can improve the dry-shrinkage resistance of the mixture [89], and the application of cement-stabilized jarofix waste can reduce the base thickness of flexible pavement [122]. Lu [123] evaluated the effect of desulfurized gypsum on the shrinkage crack resistance of CSA. The addition of desulfurized gypsum is conducive to improve the dry-shrinkage performance of CSA. When the content of desulfurized gypsum is higher than $3 \%$, the shrinkage strain of CSA is obviously reduced. Desulfurized gypsum can promote the reaction of calcium aluminate crystal to produce ettringite, realize the micro-expansion of cementitious material and weaken the dry-shrinkage phenomenon in the curing process to a certain extent.

In terms of substitution of cementitious materials, the use of steel slag, desulfurized gypsum, electric arc furnace slag and activated coal gangue is conducive to improve the crack resistance and frost resistance of CSMs [83,102,124]. Ao and Jiang [102] prepared CSM by using activated coal gangue powder instead of cement. With the increase of the replacement proportion of activated coal gangue, the base strength of CSMs first increased and then decreased, while the dry-shrinkage performance decreased. When the replacement amount of activated coal gangue is $50 \%$, the temperature-shrinkage coefficient of CSM base is the smallest. Industrial and mining waste as cementing material has a positive effect of improving the frost resistance and reducing the amount of cement. 
Table 2. Effect of industrial and mining wastes on durability of CSMs.

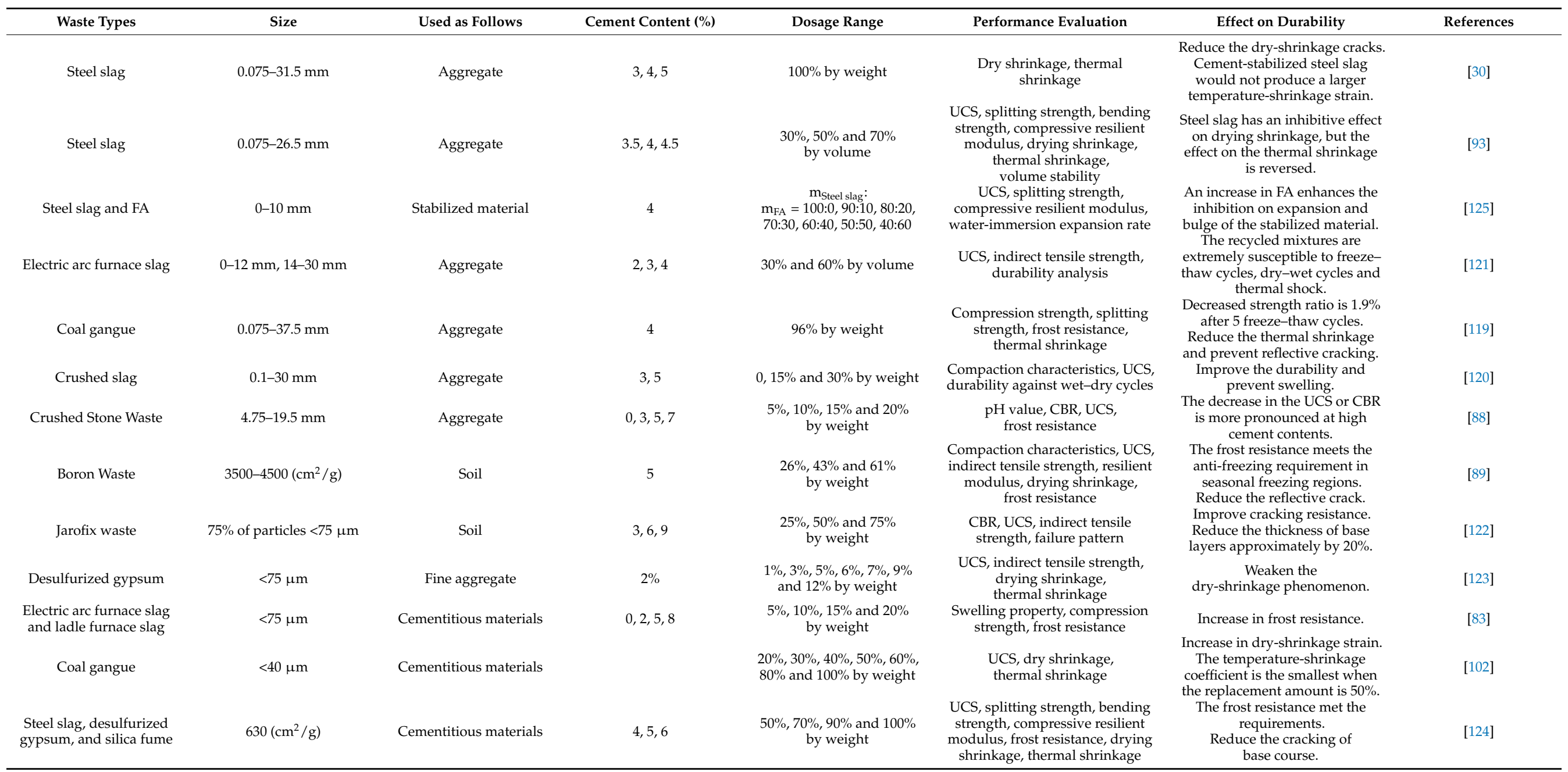




\section{2. $C D W$}

CDW is mainly used as RA in CSMs. The RA produced with CDW has the characteristics of low strength and high water absorption. Therefore, the optimal moisture content of CSRA is greater than that of CSA, and its maximum dry density is related to the type and gradation of RA $[23,94]$. The mechanical strength of CSMs decreases with the increase of CDW replacement.

The influence of CDW on the durability of CSMs is related to its sources and processing methods. RCA, RAP, CB and RMA have different effects on durability of CSM. The influence of different CDW on the durability of CSMs is shown in Table 3. The effect of different RAs on the durability of CSMs is mainly affected by particle strength, size, surface roughness and water absorption [23]. The introduction of RA may reduce the drying shrinkage, erosion resistance and frost resistance of CSMs, but it is beneficial to increase the fatigue resistance $[23,78,95,97]$. The reason may be that the cement hydration products and rough surface in RCA enhance the cementation among cement and aggregate, and then cause the fatigue damage to form microcrack-path growth.

Previous study [126] had shown that surface treatment of RA could improve frost resistance and dry shrinkage of CSRA. The treatment methods of RA include physical strengthening and chemical strengthening. The main purpose is the removal and strengthening of the adhered cement mortar on the surface of the RA. Physical methods include mechanical grinding, heavy media separation, multistage crashing and ultrasonic cleaning [127], while chemical improvement mainly uses surface treatment materials to activate the surface of RA. The surface treatment materials currently used include cement-silica fume mixtures, sodium silicate solution, acid solution, polymer solution, silicone resin and silane-coupling agent [126-129]. The physical method and acid solution treatment are mainly used to remove the loose cement mortar on the surface of RA, reduce the water absorption of aggregate and then improve the dry-shrinkage performance of CSRA. The adhesion of silicone solution to RA effectively fills the pores on the aggregate surface and closes the channel of water immersion in the RA, so as to realize the strengthening of RA. The shrinkage cracking resistance of CSMs prepared with RA treated with silicone solution is significantly improved [130]. In addition, the particulate active substances, such as silica fume, cannot only fill the pores and gaps of RA surface, but it can also react with calcium hydroxide to produce C-S-H gel, so as to enhance the bond strength between cement and RA.

The partial replacement of aggregate with CBs is beneficial to improve the cohesiveness of cement paste and aggregate in CSM, and then to improve the mechanical properties and durability. The addition of appropriate amount fine-grained CBs in CSM is conducive to improving the frost resistance and early drying crack resistance, and the increase of broken bricks is not conducive to the thermal shrinkage of CSM [3,4,23,97]. Ren et al. [94] prepared CSRA with RAP and reclaimed cement-stabilized base-course (RAI). With the increase of RAP and RAI content, the mechanical properties of CSRAs showed a downward trend. The effect of RA content and composition is more obvious in the case of high cement content. The micromorphology of different CSAs is shown in Figure 9. Compared with the natural aggregate, the RA has surface defects, and it is easier to form microcracks under stress. RAP has a greater impact on the mechanical properties of CSRA than RAI. Compared with RAP, the RAI can obtain better durability in CSRMs. The main reason is that the asphalt on RAP surface increases the interface thickness and weakens the migration of water to the aggregate surface, which reduces the hydration reaction of RAP. At the same time, there is a gap among asphalt and cement or aggregate, which is not conducive to the cementation of cement and RAI [84]. 
Table 3. Effect of CDWs addition on properties of CSAs.

\begin{tabular}{|c|c|c|c|c|c|c|c|c|c|}
\hline CDW Types & Dosage Range (\%) & $\begin{array}{c}\text { Cement Content } \\
\text { (\%) }\end{array}$ & UCS & $\begin{array}{c}\text { Drying } \\
\text { Shrinkage }\end{array}$ & $\begin{array}{l}\text { Thermal } \\
\text { Shrinkage }\end{array}$ & $\begin{array}{l}\text { Anti-Scouring } \\
\text { Performance }\end{array}$ & Frost Resistance & Fatigue Lives & References \\
\hline $\mathrm{CB}$ and RCA & $0,20,40,60,80,100$. & $3,4,5,6$ & $\begin{array}{l}\text { Increase first and } \\
\text { then decrease }\end{array}$ & $\uparrow$ & $\downarrow$ & $\downarrow$ & Not significant & $\uparrow$ & {$[23,57]$} \\
\hline $\begin{array}{l}\text { RCA } \\
\text { RCA }\end{array}$ & $\begin{array}{l}0,40,70,100 \\
0,30,60,100\end{array}$ & $\begin{array}{c}4,5,6 \\
5\end{array}$ & $\downarrow$ & $\downarrow$ & - & $\bar{\downarrow}$ & - & - & {$[95]$} \\
\hline $\mathrm{RCA}$ and $\mathrm{CB}$ & $0,20,40,60$ & 5 & $\downarrow$ & $\uparrow$ & Not significant & $\downarrow$ & $\begin{array}{l}\text { Increase first and } \\
\text { then decrease }\end{array}$ & - & [97] \\
\hline RMA & $10,18,28$ & $3,3.5,4$ & $\downarrow$ & $\downarrow$ & $\downarrow$ & $\downarrow$ & $\downarrow$ & - & [96] \\
\hline RCA & $0,30,60,90$ & 4,5 & $\downarrow$ & - & - & - & - & $\uparrow$ & [78] \\
\hline $\mathrm{CB}$ & $0,20,40,60,80,100$ & 5 & $\downarrow$ & $\uparrow$ & $\downarrow$ & - & - & $\downarrow$ & [3] \\
\hline CB & $20,40,60,80,100$. & 5 & $\downarrow$ & $\uparrow$ & $\downarrow$ & - & $\downarrow$ & - & {$[4]$} \\
\hline RCA & $0,30,60,100$ & 5 & $\uparrow$ & $\downarrow$ & $\downarrow$ & - & - & - & [130] \\
\hline RCA & $0,30,70,100$ & 10 & $\downarrow$ & $\downarrow$ & - & - & $\begin{array}{l}\text { Increase first and } \\
\text { then decrease }\end{array}$ & - & [131] \\
\hline $\mathrm{RCA}$ and $\mathrm{CB}$ & $0,25,50,75,100$ & $3,4,5$ & $\downarrow$ & $\downarrow$ & $\downarrow$ & - & - & - & [132] \\
\hline $\begin{array}{l}\text { Reclaimed } \\
\text { lime-FA } \\
\text { macadam }\end{array}$ & $0,40,60,100$ & $3,4.5,6$ & $\downarrow$ & - & - & - & $\downarrow$ & - & [133] \\
\hline
\end{tabular}

Notes: $\downarrow$ means the performance decreases, $\uparrow$ means the performance increases.

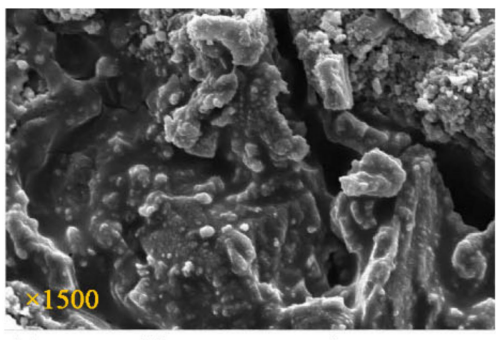

(a) CSA with $100 \%$ natural aggregates

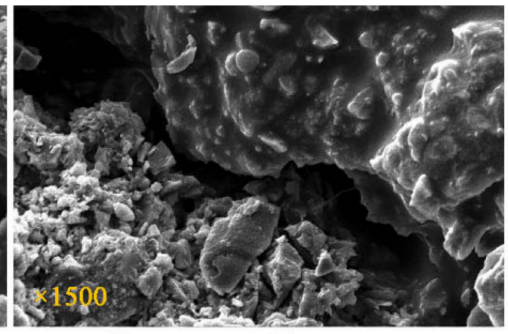

(b) CSRM with $100 \%$ RAI

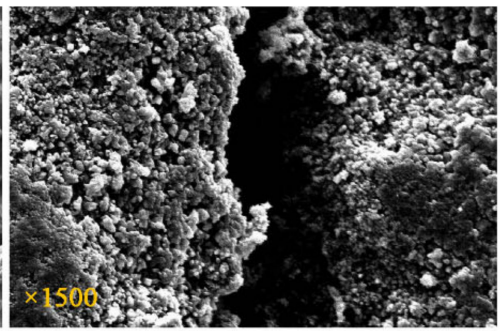

(c) CSRM with $100 \%$ RAP

Figure 9. Micromorphology of CSRCA: (a) CSA with 100\% natural aggregates, (b) CSRM with 100\% RAI and (c) CSRM with $100 \%$ RAP [94].

Considering the adverse effect of CDWs on the performance of CSAs, the maximum dosage of CDWs is generally limited in application. For example, the upper limit of RAP allowed by the Virginia center for transportation and Texas department of transportation in the United States is $30 \%$ and $20 \%$, respectively [101]. In general, the mechanical properties of CSRA are lower than that of natural aggregate. Some RA can improve the fatigue resistance of CSAs. While meeting the strength requirements of the specification, the use of RA instead of natural aggregate is conducive to the resource utilization of CDWs.

\subsection{Municipal Waste}

Due to the variety of municipal waste, its impact on the durability of CSMs is not the same. The previous study [85] indicated that with the increase of recycled glass content in CSMs, the optimum moisture content and maximum dry density of CSS decreased. It is recommended to control the dosage content of waste glass within $10 \%$. Excessive addition of waste glass to CSM can affect the adhesion among recycled glass and cement and reduce the durability of CSMs. For CSMs containing waste glass, the moisture content should be strictly controlled to ensure long fatigue life [104]. In addition, the incorporation of waste oil into CSM is conducive to improving the crack resistance of CSM. Li et al. [79] compared the effects of different waste oils on the dry-shrinkage deformation and fatigue cracking resistance of CSA. The incorporation of cooking oil, frying oil and animal fat improved the dry shrinkage and fatigue resistance of CSA. Waste oils can alleviate the bonding effect among aggregate and cement paste and promote the formation of microcracks in CSA at the initial stage of curing, which helps to release the shrinkage stress of CSA [79,105].

Yan et al. [2] investigated the effect of municipal solid waste incineration bottom ash (MSWIBA) as aggregate on the performance of CSRA, and systematically evaluated the mechanical strength, drying shrinkage and freeze-thaw resistance of CSRA containing MSWIBA. Figure 10 shows the drying-shrinkage results of CSRAs partially replacing aggregate by MSWIBA. With the increase of replacement rate of MSWIBA, the cumulative dry-shrinkage strain of CSRA first decreased and then increased. The dry shrinkage of CSRA is related to the hydration reaction of cement paste and the internal capillary pores. 
The density of MSWIBA is smaller than that of limestone aggregate. The introduction of MSWIBA reduces the proportion of cement paste in CSRA, and then it reduces the dry shrinkage caused by hydration under drying conditions. In addition, the substitution of MSWIBA increases the number of capillary pores. The addition of excessive MSWIBA is not conducive to reducing the shrinkage strain. When the substitution rate of MSWIBA increases to $30 \%$, the effect of the increase of capillary pores on dry-shrinkage strain exceeded that of the decrease of cement paste. Previous studies $[2,134,135]$ observed that the introduction of MSWIBA was not conducive to the mechanical properties and frost resistance of CSRAs, but its wear resistance, water sensitivity and drying shrinkage were improved. When municipal solid waste incineration FA is used, the cement content can be appropriately increased to ensure the durability of CSRAs and reduce the migration of potential heavy metal ions in MSWIBA [20].

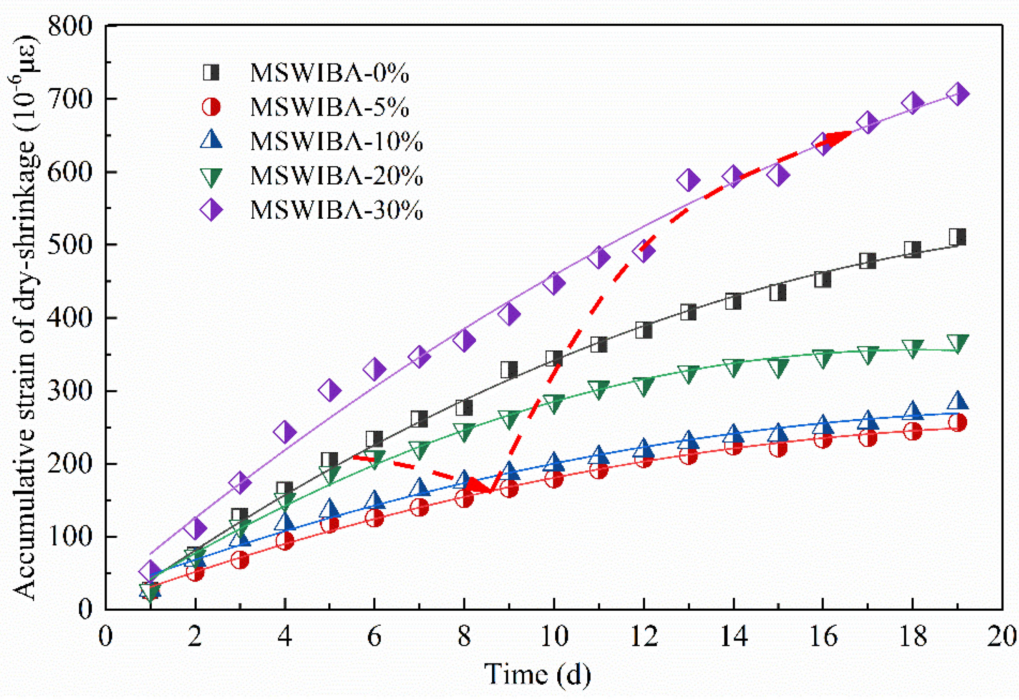

Figure 10. Dry-shrinkage coefficients of CSRAs containing MSWIBA [2].

\subsection{Waste Rubber}

Waste rubber was originally applied in cement concrete. The incorporation of waste rubber powder or particles is mainly used to improve the frost resistance and fatigue resistance of cement concrete. At the same time, cement concrete mixed with waste rubber particles exhibits an obvious toughness failure mode during compression failure, and its shrinkage resistance is enhanced $[136,137]$. Considering the low cost and excellent toughness of waste rubber, rubber products are gradually used in CSM. With the increase of waste rubber content, the optimum moisture content and maximum dry density of CSMs are gradually decreased $[34,107,111,118]$, but the toughness and fatigue life are improved, especially at a low stress level [112].

As shown in Figure 11a, the flexural tensile strength and stiffness of CSMs decrease with the increase of waste rubber particle replacement. The main reason is that the addition of waste rubber particles has an adverse effect on the aggregate crowding, which weakens the ability of the mixture to resist heavy traffic load [109]. The introduction of excessive rubber particles has negative effect on the ability to be compacted and the durability of CSMs [25]. It is worth noting that the introduction of waste rubber does not cause the formation of new hydration products, and the reduction in the interaction among the untreated rubber particle and other surrounding components is the main reason for the adverse impact on the mechanical properties [109]. Improving the surface roughness of rubber particles is conducive to improving the mechanical properties of CSMs [26]. As shown in Figure 11b, the cracks formed in the failure of CSMs containing waste rubber particles always tend to propagate through the rubber particles [25,26]. With the increase of waste rubber particle replacement, the fractal size and fracture energy of CSMs are higher. 
The crack tends to propagate through the weak point in the development process, and the crack width is narrow. The existence of rubber particles absorbs the energy generated by the crack tip, Yadav et al. [110] and Farhan et al. [21] also obtained the same conclusion. The main reason for the improvement of fatigue performance of low modulus materials such as waste rubber is that crumb rubber particles reduce local stress, which is conducive to delay crack propagation. In addition, the low modulus particles embedded in the rigid medium make the crack path tend to propagate through these weak points and extend the crack path [138]. This makes the crack distribution more uniform after the failure of CSMs, and avoids the reflection crack damage of asphalt pavement surface caused by the stress concentration of CSMs [112].

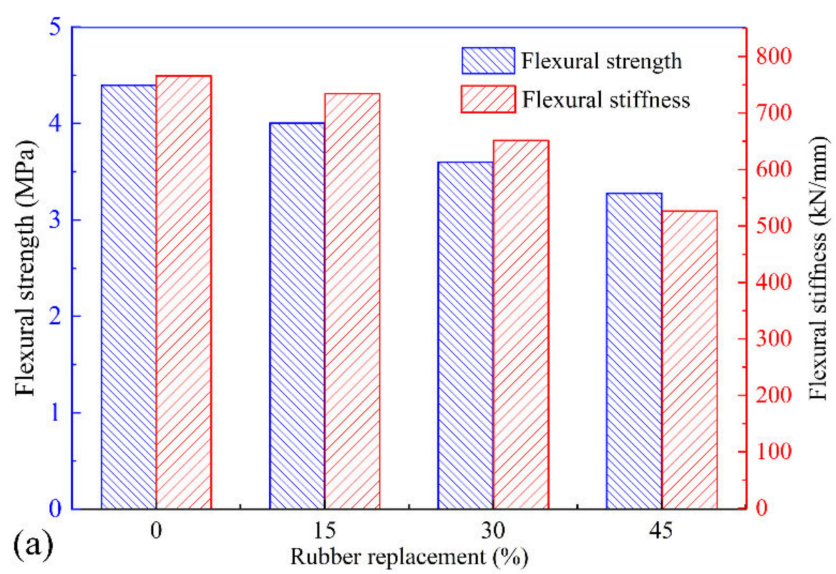

(b)

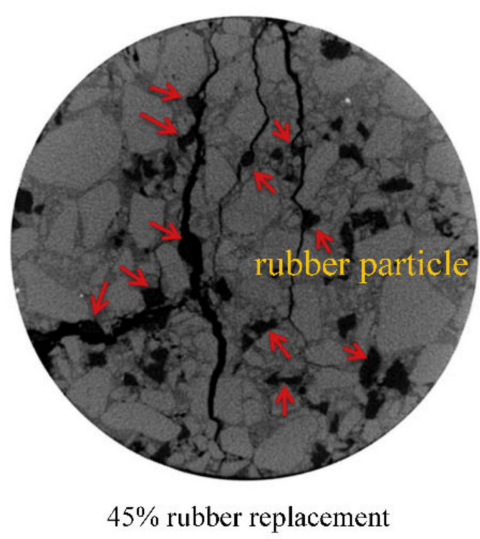

Figure 11. Influence of rubber replacement on the properties of CSM: (a) flexural tensile strength and (b) crack development $[25,64]$.

The addition of waste rubber plays a positive role in improving the frost resistance and crack resistance of CSMs $[34,38,109]$. As shown in Figure 12, with the increase of waste rubber powder content, the dry-shrinkage coefficient and temperature-shrinkage coefficient of CSA show a downward trend, and the variation range of dry-shrinkage coefficient and temperature-shrinkage coefficient decreases with the increase of curing age. This is mainly related to the hydrophobicity and high elasticity of rubber materials. The presence of rubber powder reduces the elastic modulus and the sensitivity to moisture and temperature changes of CSMs. It was also concluded in the reference [139] that materials with low elastic modulus would reduce thermal and shrinkage stress. In addition, the microcracks among coarse rubber particles and cement hydration products provide space for the development of drying-shrinkage cracks, which can effectively improve the crack resistance of CSAs [115].

\subsection{Waste Fiber}

Waste fiber used in CSMs is mainly used to improve crack resistance, scouring resistance and fatigue resistance $[27,28]$. When used in cement-stabilized special soil, waste fiber can also reduce the expansibility [140]. The interaction between the fiber and the matrix is a critical factor to control the effect of fiber reinforcement [140], and the interaction and interlocking with the aggregate is another mechanism enhancing behavior [28]. The type, content, size and dispersion degree of waste fiber affects the durability of fiber reinforced CSMs. Generally, the waste fiber content is controlled within $1 \%$. With the increase of fiber content, the optimum moisture content of CSMs increases, but the maximum dry density decreases [99]. Suleman et al. [141] found that the fatigue performance of CSMs improved with each increment in fibers content, and the maximum individual increase was observed for $0.3 \%$ fiber content, improving fatigue life by $12 \%$. Lv and Zhou [86] incorporated waste fiber cloth blocks with different amount and size into cement-stabilized sand. The incorporation of waste fiber cloth blocks improved the strength and residual shear strength 
of CSMs. The bridging effect of waste fiber can effectively prevent the further development of cracks and deformation of CSMs. The existence of waste fiber makes the potential cracks in the failure process finer and dispersed, as shown in Figure 13. Waste fiber can improve the tensile properties and toughness of CSMs, and reduce the crack propagation speed of CSM and the probability of reflective cracks [28,142]. Increasing the dispersion degree of waste fibers can improve the mechanical properties and crack resistance of CSMs. Waste fiber can reduce the modulus decay rate of CSMs under load, and then increase its fatigue life [141]. From a mechanistic pavement design point of view, the sustainable reinforcement of CSMs with waste fibers will reduce the required pavement thickness or save the maintenance costs [28]. It is worth noting that the waste fiber should not be too long to avoid agglomeration or entanglement of mixing machinery in the mixing process of CSMs [140]. In addition, the main recovery methods of waste fiber include mechanical recycling, thermal processes and chemical processes [143]. With the recovery process of waste fiber, it is difficult to ensure the effective removal of residues on the surface of waste fiber [144]. The residues have an adverse impact on the interaction among waste fiber and surrounding materials in CSMs, and then affect the improvement of crack resistance of fiber-reinforced CSMs.
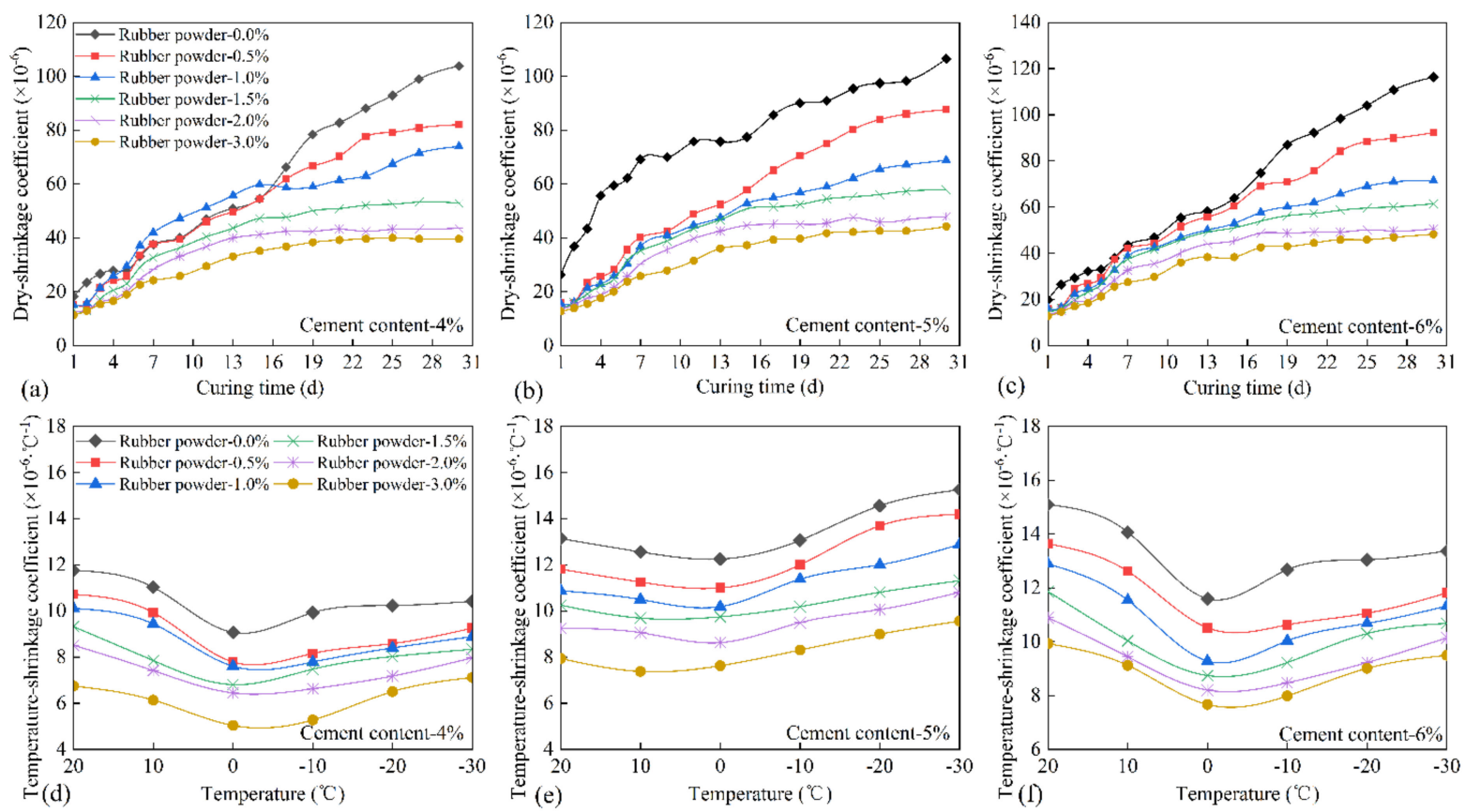

Figure 12. Variation of dry-shrinkage coefficient and temperature-shrinkage coefficient of CSM with different rubber-powder contents: (a) dry-shrinkage coefficient of CSA with $4 \%$ cement content, (b) dry-shrinkage coefficient of CSA with 5\% cement content, (c) dry-shrinkage coefficient of CSA with $6 \%$ cement content, (d) temperature-shrinkage coefficient of CSA with $4 \%$ cement content, (e) temperature-shrinkage coefficient of CSA with $5 \%$ cement content, and (f) temperature-shrinkage coefficient of CSA with $6 \%$ cement content [38]. 

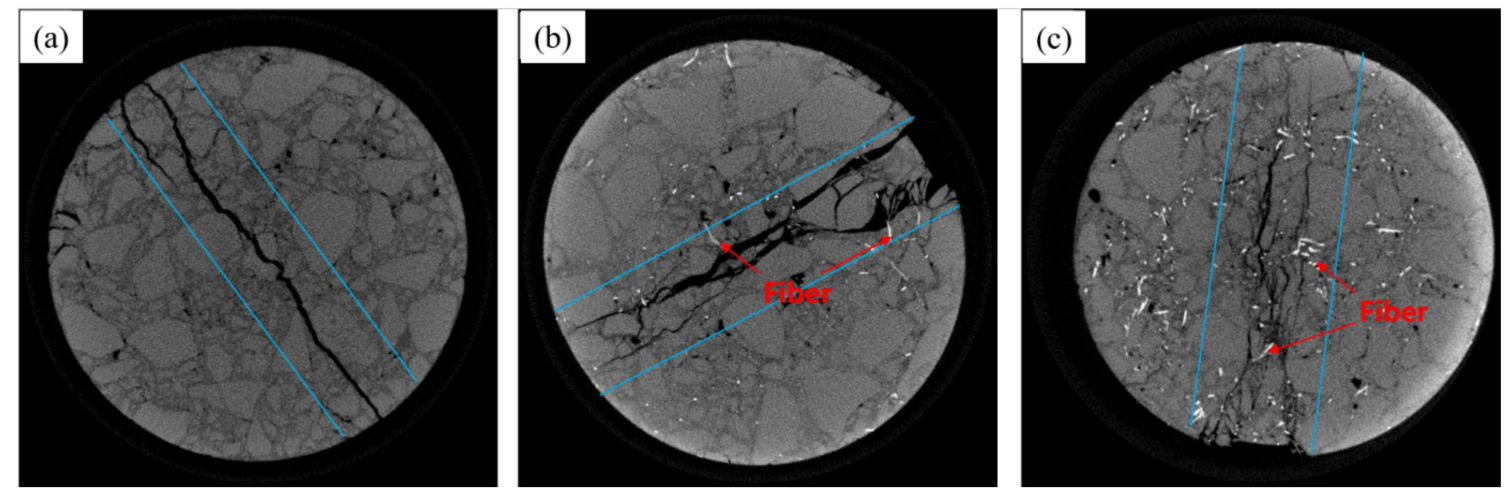

Figure 13. X-ray sample images of failed specimens: (a) CSM with 7\% cement, (b) CSM with 7\% cement and $0.25 \%$ fibers and (c) CSM with $7 \%$ cement and $0.75 \%$ fibers [28].

\section{Challenges in Sustainable Development of CSMs}

The durability improvement of CSMs and the harmless treatment of waste materials in CSMs will continue to become a research hotspot in the future. Although various studies have been conducted on the durability improvement and sustainable development of CSMs, with the continuous implementation of the concept of green development and the continuous improvement of road construction requirements, the sustainable development and application of CSMs based on the utilization of waste materials are still facing some challenges. The challenges may be as follows:

1. A variety of waste materials have been used in the preparation of CSMs and achieved good performance in previous studies. However, more waste materials should be utilized in CSMs to promote the sustainability of transportation infrastructure construction and reduce the amount of waste materials.

2. Compared with traditional CSMs, the introduction of waste materials may have adverse effects on the mechanical properties and durability of CSMs, which also limits the engineering application of some waste materials to prepare CSMs.

3. The durability of CSMs are affected by the composition, specification and proportion of waste materials. Therefore, it is necessary to establish the selection and pretreatment standards for different waste materials according to the requirements of CSMs for raw materials, so as to promote the large-scale application of waste resources on the basis of ensuring the performance of CSMs.

4. There are many types of waste materials used to replace aggregate, filler, cementitious materials and admixtures in CSMs. Based on the engineering characteristics of different waste materials, it is urgent to realize the comprehensive utilization of a variety of waste materials in CSMs, which is very important to promote the cementless and low-carbon development of CSMs.

5. Some solid waste materials contain trace pollutants, although previous studies have shown that heavy metal ions can be effectively stabilized in CSMs. However, with the failure of CSMs, the long-term effects of heavy metal ions in different solid waste materials on groundwater and soil around roads still need to be evaluated.

\section{Conclusions}

With the continuous improvement of road-performance requirements, it is still the first choice for most countries and regions to apply CSMs in the base and subgrade. The utilization of waste materials is conducive to the sustainable development of road CSMs. This review summarized the influence of different waste materials on the durability of CSMs and the measures to improve the durability of CSMs. The research progress of durability and sustainable development direction of road CSMs was clarified. The main conclusions are as follows: 
1. The cracks of CSMs include shrinkage cracks and fatigue cracks. Gradation, molding method, cement content, moisture content and filler less than $0.075 \mathrm{~mm}$ can significantly affect the crack resistance of CSMs. The proper addition of rubber particles, metakaolin and fiber can improve the crack resistance of CSMs. The drying-shrinkage cracks of CSMs mainly occur in the first three days after construction. Moisture preservation and pre-cracking treatment are beneficial to reduce the early dryingshrinkage cracks.

2. The main factor affecting the anti-erosion performance of CSS is cement dosage, while the factors affecting the anti-erosion performance of CSA include fine material combination, coarse aggregate gradation and water permeability. The dynamic water erosion of CSAs can be reduced by reducing the content of fine particles, introducing waste fibers, increasing the degree of bonding and increasing the porosity.

3. To improve the frost resistance of CSMs, the structure and material composition can be optimized, such as reducing the void ratio, increasing the cement content appropriately and adding the auxiliary materials with toughening effect. In addition, strengthened curing conditions and waterproof measures are also conducive to improving the frost resistance.

4. The fatigue life of CSM base has a strong correlation with the tensile state of the bottom of structural layer. The fatigue failure models of CSMs can be divided into strain-based fatigue model and stress-based fatigue model. Enhancing adhesion among aggregate and cementitious materials is the key point to improve the fatigue resistance of CSMs. It is of positive significance to appropriately extend the curing time of CSMs in order to improve fatigue life.

5. Waste materials used for CSMs include mining and industrial waste, CDW, municipal waste, waste rubber, waste fiber and so on. Some activated industrial and mining waste can be utilized as cementitious materials to promote cement reduction of CSMs. The utilization of waste materials is an important direction to promote the sustainable development of CSMs, which is conducive to the harmless treatment of waste materials.

6. The introduction of RCA may reduce the drying shrinkage, erosion resistance and frost resistance of CSMs, but it is beneficial to improve the fatigue life. The surface treatment of RA can improve the crack resistance and frost resistance of CSRA.

7. The amount of waste glass and MSWIBA used in CSMs should be controlled. A too-high amount is not conducive to the durability of CSMs. It is not conducive to the durability of CSMs when the incorporation amount is too high. Adding a proper amount of waste oil can improve the dry-shrinkage resistance and fatigue resistance of CSMs.

8. The addition of waste rubber and fiber can improve the crack resistance and fatigue resistance of CSMs, but the action mechanism is different. The addition of wasterubber particles can reduce the strength and modulus of CSMs, but it also increases the toughness of CSMs and extends the path of microcrack development. The introduction of waste fiber enhances the flexural tensile properties of CSMs. Improving the surface roughness of waste rubber and fiber is conducive to improving the durability of CSMs.

Author Contributions: Conceptualization, P.W. and C.W; investigation, P.W., L.N. and H.C.; writingoriginal draft preparation, P.W. and L.N; writing - review and editing, C.W. and L.S.; visualization, L.N. and H.C; formal analysis, H.C.; supervision, C.W. and L.S.; funding acquisition, P.W. and C.W. All authors have read and agreed to the published version of the manuscript.

Funding: This research was funded by Fundamental Research Funds for the Central Universities, CHD (Program Nos. 300102210705 and 300102219314 ), Shaanxi Province Key Research \& Development Plan (2021GY-206), Transportation Department Science and Technology Project in Xinjiang Uygur Autonomous Region of China (2019-ZD1-015) and Transportation Department Science and Technology Project in Ministry of Transport of the People's Republic of China (2019-MS1-024). The sponsorship and interest are gratefully acknowledged. 
Institutional Review Board Statement: Not applicable.

Data Availability Statement: All data used in this research can be provided upon request.

Acknowledgments: In this section, you can acknowledge any support given which is not covered by the author contribution or funding sections. This may include administrative and technical support, or donations in kind (e.g., materials used for experiments).

Conflicts of Interest: The authors declare that they have no conflicts of interest regarding the publication of this paper.

\section{References}

1. Pourkhorshidi, S.; Sangiorgi, C.; Torreggiani, D.; Tassinari, P. Using recycled aggregates from construction and demolition waste in unbound layers of pavements. Sustainability 2020, 12, 9386. [CrossRef]

2. Yan, K.Z.; Sun, H.; Gao, F.Q.; Ge, D.D.; You, L.Y. Assessment and mechanism analysis of municipal solid waste incineration bottom ash as aggregate in cement stabilized macadam. J. Clean. Prod. 2020, 244, 118750. [CrossRef]

3. Hou, Y.Q.; Ji, X.P.; Zou, L.; Liu, S.; Su, X.L. Performance of cement-stabilised crushed brick aggregates in asphalt pavement base and subbase applications. Road Mater. Pavement 2016, 17, 120-135. [CrossRef]

4. Hu, L.Q.; Sha, A.M. Performance test of cement stabilized crushed clay brick for road base material. China J. Highw. Transp. 2012, $25,73-79$.

5. Wang, Y.; Ni, F.J.; Li, Z.X. Fatigue performance of cement-stabilized macadam mixture. J. Traff. Transp. Eng. 2009, 9, 10-14.

6. Sha, A.M. Material characteristics of semi-rigid base. China J. Highw. Transp. 2008, 21, 1-5.

7. Hao, P.W.; Hu, C.S.; Zhang, B.Q.; Huang, Y.J. Study on anti-brushing performance of semi-rigid base course. J. Xi'an Highw. Univ. 2000, 20, 9-11.

8. Wang, Y.Q.; Tan, Y.Q.; Wang, X.L. Study on fatigue characteristics of freeze-thaw damage of cement stabilized macadam. Highway 2017, 62, 239-242.

9. Ji, X.P.; Wang, T.; Zhou, H.Z.; Zhang, Y.L. Mechanical and fatigue properties as well as strength criteria of cement stabilized gravel produced by vibration compaction method. J. Build. Mater. 2018, 21, 761-767.

10. Huber, M.; Welker, A.; Helmreich, B. Critical review of heavy metal pollution of traffic area runoff: Occurrence, influencing factors, and partitioning. Sci. Total Environ. 2016, 541, 895-919. [CrossRef] [PubMed]

11. Marzouk, M.; El-zayat, M.; Aboushady, A. Assessing environmental impact indicators in road construction projects in developing countries. Sustainability 2017, 9, 843. [CrossRef]

12. Bamigboye, G.O.; Bassey, D.E.; Olukanni, D.O.; Ngene, B.; Adegoke, D.; Odetoyan, A.O.; Kareem, M.A.; Enabulele, D.O.; Nworgu, A.T. Waste materials in highway applications: An overview on generation and utilization implications on sustainability. J. Clean. Prod. 2021, 283, 124581. [CrossRef]

13. Chen, M.; Wen, P.H.; Wang, C.H.; Chai, Z.; Gao, Z.W. Evaluation of particle size distribution and mechanical properties of mineral waste slag as filling material. Constr. Build. Mater. 2020, 253, 119183. [CrossRef]

14. Thakare, A.A.; Singh, A.; Gupta, V.; Siddique, S.; Chaudhary, S. Sustainable development of self-compacting cementitious mixes using waste originated fibers: A review. Resour. Conserv. Recy. 2021, 168, 105250. [CrossRef]

15. Wesolowski, M.; Wlodarski, P.; Iwanowski, P.; Kowalewska, A. Analysis and assessment of the usefulness of recycled plastic materials for the production of airfield geocell. Materials 2021, 14, 3557. [CrossRef]

16. Wang, C.H.; Chen, Q.; Guo, T.T.; Li, Q. Environmental effects and enhancement mechanism of graphene/tourmaline composites. J. Clean. Prod. 2020, 262, 121313. [CrossRef]

17. Torretta, V.; Rada, E.C.; Ragazzi, M.; Trulli, E.; Istrate, I.A.; Cioca, L.I. Treatment and disposal of tyres: Two EU approaches. A review. Waste Manag. 2015, 45, 152-160. [CrossRef]

18. Wang, C.H.; Wang, S.; Gao, Z.W.; Song, Z. Effect evaluation of road piezoelectric micro-energy collection-storage system based on laboratory and on-site tests. Appl. Energy 2021, 287, 116581. [CrossRef]

19. Bertelsen, I.M.G.; Ottosen, L.M.; Fischer, G. Influence of fibre characteristics on plastic shrinkage cracking in cement-based materials: A review. Constr. Build. Mater. 2020, 230, 116769. [CrossRef]

20. Yan, K.Z.; Gao, F.Q.; Sun, H.; Ge, D.D.; Yang, S. Effects of municipal solid waste incineration fly ash on the characterization of cement-stabilized macadam. Constr. Build. Mater. 2019, 207, 181-189. [CrossRef]

21. Farhan, A.H.; Dawson, A.R.; Thom, N.H. Effect of cementation level on performance of rubberized cement-stabilized aggregate mixtures. Mater. Des. 2016, 97, 98-107. [CrossRef]

22. Guo, Y.X.; Li, C.; Li, M. Experimental study on cement stabilized macadam-gangue mixture in road base. Int. J. Coal. Prep. Util. 2019. [CrossRef]

23. Xiao, J.; Chen, Q.; Wu, C.F.; Sun, Y.C.; Long, C.J. Fatigue performance of cement stabilized recycled brick and concrete aggregate(RBCA) mixtures. J. Build. Mater. 2019, 22, 922-927.

24. Li, L.G.; Xiao, B.F.; Fang, Z.Q.; Xiong, Z.; Chu, S.H.; Kwan, A.K.H. Feasibility of glass/basalt fiber reinforced seawater coral sand mortar for 3D printing. Addit. Manuf. 2021, 37, 101684. 
25. Farhan, A.H.; Dawson, A.R.; Thom, N.H. Characterization of rubberized cement bound aggregate mixtures using indirect tensile testing and fractal analysis. Constr. Build. Mater. 2016, 105, 94-102. [CrossRef]

26. Farhan, A.H.; Dawson, A.R.; Thom, N.H. Compressive behaviour of rubberized cement-stabilized aggregate mixtures. Constr. Build. Mater. 2020, 262, 120038. [CrossRef]

27. He, X.B.; Yang, Q.G.; He, G.J. Anti-erosion property of polypropylene fiber reinforced cement-stabilized macadam base material. J. Build. Mater. 2010, 13, 263-267.

28. Farhan, A.H.; Dawson, A.R.; Thom, N.H. Recycled hybrid fiber-reinforced \& cement-stabilized pavement mixtures: Tensile properties and cracking characterization. Constr. Build. Mater. 2018, 179, 488-499.

29. Ji, X.P.; Cao, H.L.; Liu, P.Q. Performances and influencing factors of cement stabilized recycled concrete aggregate. J. Build. Mater. 2016, 19, 342-346.

30. Li, W.; Lang, L.; Lin, Z.Y.; Wang, Z.H.; Zhang, F.G. Characteristics of dry shrinkage and temperature shrinkage of cement-stabilized steel slag. Constr. Build. Mater. 2017, 134, 540-548. [CrossRef]

31. Zheng, Y.X.; Zhang, P.; Cai, Y.C.; Jin, Z.Q.; Moshtagh, E. Cracking resistance and mechanical properties of basalt fibers reinforced cement-stabilized macadam. Compos. B. Eng. 2019, 165, 312-334. [CrossRef]

32. Zhang, J.P.; Cui, S.C.; Cai, J.; Pei, J.Z.; Jia, Y.S. Life-cycle reliability evaluation of semi-rigid materials based on modulus degradation model. KSCE J. Civ. Eng. 2018, 22, 2043-2054. [CrossRef]

33. Liao, X.F.; Chen, Z.D.; Jiang, Y.J.; Lei, M.J. Research on cracking of cement-stabilized macadam base during highway construction. J. Guangxi U. (Nat. Sci. Ed.) 2012, 37, 716-722.

34. Lv, S.T.; Wang, S.S.; Wang, P.P.; Liu, C.C.; Zhao, D.D. Strength and toughness of rubber-cement stabilized macadam. China J. Highw. Transp. 2020, 33, 139-147.

35. Wu, Z.L.; Zhu, X.Y.; Deng, Y.F.; Liu, H.S.; Zha, P.S. Behavior and micro-mechanism of cement-based modified compaction soil composed of steel slag and metakaolin. China J. Highw. Transp. 2017, 30, 18-26.

36. Güneyisi, E.; Gesoğlu, M.; Mermerdaş, K. Improving strength, drying shrinkage, and pore structure of concrete using metakaolin. Mater. Struct. 2008, 41, 937-949. [CrossRef]

37. Du, S.W. Mechanical properties and shrinkage characteristics of cement stabilized macadam with asphalt emulsion. Constr. Build. Mater. 2019, 203, 408-416. [CrossRef]

38. Wang, H.P.; Wang, P. Experiment on road performance of rubber powder cement stabilized aggregate base course. J. Highw. Transp. Res. Dev. 2013, 30, 12-16+22.

39. Liu, Z.J.; Wang, D.Q.; Wei, X.B.; Wang, L.L. Impact of fiber diameter on-road performance of cement-stabilized macadam. Balt. J. Road Bridge E. 2017, 12, 12-20. [CrossRef]

40. Sha, A.M.; Hu, L.Q. Structural characteristics of semi-rigid base course material. China J. Highw. Transp. 2008, $21,1-5+42$.

41. Wang, L.; Xie, X.G.; Yu, L.Z. Influence of different compacting methods on mix design of semi-rigid base materials. J. Highw. Transp. Res. Dev. 2013, 30, 32-37.

42. Li, L.H.; Huang, P.; Liu, D. Impact on performance of cement stabilized macadam mixtures between gyratory compaction and static compaction methods. J. Chang'an U. (Nat. Sci. Ed.) 2016, 36, 17-25.

43. Liu, D.; Li, L.H. Experiment on gyratory compaction of cement stabilized base course materials. China J. Highw. Transp. 2019, 32, $118-128$.

44. Tan, H.H.; Cai, X.; Wang, H.L.; Huang, K.; Wu, S.H. A design method of cement stabilized recycled aggregate based on rotary compaction. J. Highw. Transp. Res. Dev. 2017, 34, 13-18.

45. Deng, C.Q.; Jiang, Y.J.; Tian, T.; Chen, Z.J. Resilient modulus and influencing factors of vertical vibration compacted cementstabilized macadam. Int. J. Pavement Eng. 2019, 22, 1-11. [CrossRef]

46. Duan, K.R.; Gao, Y.L.; Yao, H.; Zeng, W.; Xu, Y.S.; Zhou, W.J.; Pei, G.P.; He, B. Comparison of performances of early aged pre-vibrated cement-stabilized macadam formed by different compactions. Constr. Build. Mater. 2020, 239, 117682. [CrossRef]

47. Gao, J.Q.; Jin, P.P.; Sheng, Y.X.; An, P. A case study on crack propagation law of cement stabilised macadam base. Int. J. Pavement Eng. 2020, 21, 516-523. [CrossRef]

48. Venquiaruto, S.; da Silva, L.B.; Dal Molin, D.C.C. Influence of preloading-induced microcracking on the durability of concrete produced with different types of cement. Constr. Build. Mater. 2018, 189, 777-786. [CrossRef]

49. Mitiche_Kettab, R.; Boulanouar, A.; Bali, A. Experimental Study of the Precracking. In 7th RILEM International Conference on Cracking in Pavements.; Scarpas, A., Kringos, N., Al-Qadi, I., A., L., Eds.; Springer: Dordrecht, The Netherlands, 2012; Volume 4 , pp. 21-30.

50. Li, L.G.; Zheng, J.Y.; Ng, P.L.; Kwan, A.K.H. Synergistic cementing efficiencies of nano-silica and micro-silica in carbonation resistance and sorptivity of concrete. J. Build. Eng. 2021, 33, 101862. [CrossRef]

51. Hu, L.Q.; Sha, A.M. Experiment and mechanism analysis for anti-erosion of cement stabilized soil material base-course of bitu minous pavement. China J. Highw. Transp. 2003, 16, 16-19.

52. Zhu, T.L.; Tan, Z.M.; Zhou, Y.M. Experimental research on erosion-resistance performances of cement stabilized base materials. J. Build. Mater. 2012, 15, 565-569.

53. Sha, A.M.; Hu, L.Q. Study of the testing method for antirerosion properties of semi-rigid base materials. China J. Highw. Transp. 2002, 15, 7-10. 
54. Zhong, K.Z.; Xu, B.; Fang, Z.; Ma, T.; Huang, X.M. Shrinkage characteristic of crushed gravel cement stabilized base. J. Southeast U. (Nat. Sci. Ed.) 2020, 50, 630-636.

55. Chen, K.; Sun, F.; Liang, S.; Zhang, H.T. Experimental study on frost resistance and crack resistance of bases in cold areas based on vibration mixing technology. Mater. Rep. 2021, 35, 291-296.

56. Gao, W.; Cui, W.; Li, X.F. Experiment and analysis of anti-erosion performance of semi-rigid base surface. J. Highw. Transp. Res. Dev. 2018, 35, 1-7.

57. Xiao, J.; Wu, C.F.; Shen, Z.H.; Tan, X.G.; Dong, W.J. Research on performances of cement stabilized brick and concrete recycled aggregate base. China J. Highw. Transp. 2017, 30, 25-32.

58. Song, L.; Song, Z.; Wang, C.H.; Wang, X.C.; Yu, G.X. Arch expansion characteristics of highway cement-stabilized macadam base in Xinjiang, China. Constr. Build. Mater. 2019, 215, 264-274. [CrossRef]

59. Xu, B.; Yang, Z.H.; Zhao, L.H.; Cao, D.W.; Zhang, H.Y.; Shi, X. Study on the antifreeze performance of porous cement stabilized macadam. Constr. Build. Mater. 2019, 208, 13-22. [CrossRef]

60. Wang, Y.Q.; Tan, Y.Q.; Guo, M.; Liu, Z.Y.; Wang, X.L. Study on the dynamic compressive resilient modulus and frost resistance of semi-rigid base materials. Road Mater. Pavement 2017, 18, 259-269. [CrossRef]

61. Wang, Y.Q.; Tan, Y.Q.; Guo, M.; Wang, X.L. Effect of freeze-thaw cycles on the internal structure and performance of semirigid base materials. Adv. Mater. Sci. Eng. 2017, 2017, 7802024. [CrossRef]

62. Li, L.G.; Feng, J.J.; Zhu, J.; Chu, S.H.; Kwan, A.K.H. Pervious concrete: Effects of porosity on permeability and strength. Mag. Concr. Res. 2021, 73, 69-79. [CrossRef]

63. Hu, L.; Hao, J.; Wang, L. Laboratory evaluation of cement treated aggregate containing crushed clay brick. J. Traffic Transp. Eng. (Engl. Ed.) 2014, 1, 371-382. [CrossRef]

64. Farhan, A.H.; Dawson, A.R.; Thom, N.H.; Adam, S.; Smith, M.J. Flexural characteristics of rubberized cement-stabilized crushed aggregate for pavement structure. Mater. Des. 2015, 88, 897-905. [CrossRef]

65. Wang, Y.Q.; Tan, Y.Q.; Guo, M.; Wang, X.L. Influence of emulsified asphalt on the mechanical property and microstructure of cement-stabilized gravel under freezing and thawing cycle conditions. Materials 2017, 10, 504. [CrossRef]

66. Xu, Y.L.; Yang, G.; Zhao, H.Y. Compressive strength gain behavior and prediction of cement-stabilized macadam at low temperature curing. J. Adv. Transp. 2020, 2020, 2469436. [CrossRef]

67. Hernando, D.; del Val, M.A. Guidelines for the design of semi-rigid long-life pavements. Int. J. Pavement Res. Technol. 2016, 9 , 121-127. [CrossRef]

68. Nussbaum, P.J.; Larsen, T. Load-deflection characteristics of soil-cement pavements. 1965. Available online: https://onlinepubs. trb.org/Onlinepubs/hrr/1965/86/86-001.pdf (accessed on 24 September 2021).

69. Sha, A.M.; Jia, K.; Li, X.G. Fatigue performances of semi-rigid base course materials. J. Traff. Transp. Eng. 2009, 9, 29-33.

70. Huang, Q.L.; Quan, C.J.; Yang, Z.; Yu, L. Fatigue performance of emulsified asphalt cement stabilized macadam. J. Build. Mater. 2017, 20, 739-744

71. Lv, S.T.; Xia, C.D.; You, L.Y.; Wang, X.F.; Li, J.L.; Zheng, J.L. Unified fatigue characteristics model for cement-stabilized macadam under various loading modes. Constr. Build. Mater. 2019, 223, 775-783. [CrossRef]

72. Lv, S.T.; Zhen, J.L.; Zhong, W.L. Characteristics of strength, modulus and fatigue damage for cement stabilized macadam in curing period. China J. Highw. Transp. 2015, 28, 9-15.

73. Biswal, D.R.; Sahoo, U.C.; Dash, S.R. Fatigue characteristics of cement-stabilized granular lateritic soils. J. Transp. Eng B-Pave. 2020, 146, 04019038. [CrossRef]

74. Jameson, G.; Sharp, K.; Yeo, R. Cement-Treated Crushed Rock Pavement Fatigue Under Accelerated Loading: The Mulgrave (Victoria) Alf Trial, 1989/1991; Australian Road Research Board: Vermont South, VIC, Australia, 1992.

75. Austroads, Guide to Pavement Technology. 2: Pavement Structural Design. 2012. Available online: https://austroads.com.au/ publications / pavement/agpt02 (accessed on 24 September 2021).

76. Olidid, C.; Hein, D. Guide for the mechanistic-empirical design of new and rehabilitated pavement structures. In Proceedings of the 2004 Annual Conference and Exhibition of the Transportation Association of Canada-Transportation Innovation-Accelerating the Pace, Quebec, QC, Canada, 19-22 September 2004.

77. Corté, J.F.; Goux, M.T. Design of pavement structures: The French technical guide. Transp. Res. Rec. 1996, 1539, 116-124. [CrossRef]

78. Hou, Y.Q.; Ji, X.P.; Su, X.L. Mechanical properties and strength criteria of cement-stabilised recycled concrete aggregate. Int. J. Pavement Eng. 2019, 20, 339-348. [CrossRef]

79. Li, X.L.; Lv, X.C.; Wang, W.Q.; Liu, J.; Yu, M.; You, Z.P. Crack resistance of waste cooking oil modified cement stabilized macadam. J. Clean. Prod. 2020, 243, 118525. [CrossRef]

80. Wang, X.; Fang, N.; Ye, H.; Zhao, J. Fatigue damage analysis of cement-stabilized base under construction loading. Appl. Sci. Basel 2018, 8, 2263. [CrossRef]

81. Ma, Y.H.; Gu, J.Y.; Li, Y.; Li, Y.C. The bending fatigue performance of cement-stabilized aggregate reinforced with polypropylene filament fiber. Constr. Build. Mater. 2015, 83, 230-236. [CrossRef]

82. Xie, J.W.; Tang, L.M.; Lv, S.T.; Zhang, N.T.; Huang, T.; Liu, H.F. Standardization of fatigue characteristics of cement-treated aggregate base materials under different stress states. Appl. Sci. Basel 2018, 8, 1500. [CrossRef] 
83. Parsaei, M.; Vakili, A.H.; Salimi, M.; Farhadi, M.S.; Falamaki, A. Effect of electric arc and ladle furnace slags on the strength and swelling behavior of cement-stabilized expansive clay. Bull. Eng. Geol. Environ. 2021, 80, 6303-6320. [CrossRef]

84. Ji, X.P.; Jiang, Y.J.; Liu, Y.J. Evaluation of the mechanical behaviors of cement-stabilized cold recycled mixtures produced by vertical vibration compaction method. Mater. Struct. 2016, 49, 2257-2270. [CrossRef]

85. Pacheco-Torres, R.; Varela, F. Mechanical performance of cement-stabilised soil containing recycled glass as road base layer. Road Mater. Pavement 2019, 21, 2247-2263. [CrossRef]

86. Lv, X.F.; Zhou, H.Y. Shear characteristics of cement-stabilized sand reinforced with waste polyester fiber fabric blocks. Adv. Mater. Sci. Eng. 2019, 2019, 3758413. [CrossRef]

87. Chen, M.; Shen, S.L.; Arulrajah, A.; Wu, H.N.; Hou, D.W.; Xu, Y.S. Laboratory evaluation on the effectiveness of polypropylene fibers on the strength of fiber-reinforced and cement-stabilized Shanghai soft clay. Geotext. Geomembr. 2015, 43, 515-523. [CrossRef]

88. Salehi, M.; Bayat, M.; Saadat, M.; Nasri, M. Experimental study on mechanical properties of cement-stabilized soil blended with crushed stone waste. KSCE J. Civ. Eng. 2021, 25, 1974-1984. [CrossRef]

89. Zhang, Y.T.; Guo, Q.L.; Li, L.L.; Jiang, P.; Jiao, Y.B.; Cheng, Y.C. Reuse of boron waste as an additive in road base material. Materials 2016, 9, 416. [CrossRef] [PubMed]

90. Wang, C.H.; Fu, H.; Fan, Z.T.; Li, T.Y. Utilization and properties of road thermal resistance aggregates into asphalt mixture. Constr. Build. Mater. 2019, 208, 87-101. [CrossRef]

91. Long, G.C.; Li, L.H.; Li, W.G.; Ma, K.L.; Dong, W.K.; Bai, C.N.; Zhou, J.L. Enhanced mechanical properties and durability of coal gangue reinforced cement-soil mixture for foundation treatments. J. Clean. Prod. 2019, 231, 468-482. [CrossRef]

92. Du, Y.J.; Jiang, N.J.; Liu, S.Y.; Horpibulsuk, S.; Arulrajah, A. Field evaluation of soft highway subgrade soil stabilized with calcium carbide residue. Soils Found. 2016, 56, 301-314. [CrossRef]

93. Liu, J.Z.; Yu, B.; Wang, Q. Application of steel slag in cement treated aggregate base course. J. Clean. Prod. 2020, $269,121733$. [CrossRef]

94. Ren, J.L.; Wang, S.Y.; Zang, G.Y. Effects of recycled aggregate composition on the mechanical characteristics and material design of cement stabilized cold recycling mixtures using road milling materials. Constr. Build. Mater. 2020, 244, 118329. [CrossRef]

95. Li, Q.F.; Hu, J. Mechanical and durability properties of cement-stabilized recycled concrete aggregate. Sustainability 2020, $12,7380$. [CrossRef]

96. Liu, S.J.; Zhou, S.B.; Peng, A.H.; Xuan, W.A.; Li, W. Analysis of the performance and mechanism of desulfurized rubber and low-density polyethylene compound-modified asphalt. J. Appl. Polym. Sci. 2019, 136, 48194. [CrossRef]

97. Miao, Y.H.; Yu, W.X.; Hou, Y.; Liu, C.; Wang, L.B. Influences of clay brick particles on the performance of cement stabilized recycled aggregate as pavement base. Sustainability 2018, 10, 3505. [CrossRef]

98. Estabragh, A.R.; Namdar, P.; Javadi, A.A. Behavior of cement-stabilized clay reinforced with nylon fiber. Geosynthetics International 2012, 19, 85-92. [CrossRef]

99. Tran, K.Q.; Satomi, T.; Takahashi, H. Improvement of mechanical behavior of cemented soil reinforced with waste cornsilk fibers. Constr. Build. Mater. 2018, 178, 204-210. [CrossRef]

100. Zare, P.; Narani, S.S.; Abbaspour, M.; Fahimifar, A.; Hosseini, S.M.M.M.; Zare, P. Experimental investigation of non-stabilized and cement-stabilized rammed earth reinforcement by Waste Tire Textile Fibers (WTTFs). Constr. Build. Mater. 2020, $260,120432$. [CrossRef]

101. Gautam, P.K.; Kalla, P.; Jethoo, A.S.; Agrawal, R.; Singh, H. Sustainable use of waste in flexible pavement: A review. Constr. Build. Mater. 2018, 180, 239-253. [CrossRef]

102. Ao, Q.W.; Jiang, Z. Activation of coal gangue and its application in cement stabilized macadam base. J. China Foreign Highw. 2016, $36,331-334$.

103. Topini, D.; Toraldo, E.; Andena, L.; Mariani, E. Use of recycled fillers in bituminous mixtures for road pavements. Constr. Build. Mater. 2018, 159, 189-197. [CrossRef]

104. Arulrajah, A.; Disfani, M.M.; Haghighi, H.; Mohammadinia, A.; Horpibulsuk, S. Modulus of rupture evaluation of cement stabilized recycled glass/recycled concrete aggregate blends. Constr. Build. Mater. 2015, 84, 146-155. [CrossRef]

105. Zhou, J.; Zeng, M.L.; Chen, Y.L.; Zhong, M.W. Evaluation of cement stabilized recycled concrete aggregates treated with waste oil and asphalt emulsion. Constr. Build. Mater. 2019, 199, 143-153. [CrossRef]

106. Yan, K.Z.; Li, L.L.; Zheng, K.G.; Ge, D.D. Research on properties of bitumen mortar containing municipal solid waste incineration fly ash. Constr. Build. Mater. 2019, 218, 657-666. [CrossRef]

107. Yadav, J.S.; Tiwari, S.K. Effect of waste rubber fibres on the geotechnical properties of clay stabilized with cement. Appl. Clay Sci. 2017, 149, 97-110. [CrossRef]

108. Ho, M.H.; Chan, C.M.; Bakar, I. One dimensional compressibility characteristics of clay stabilised with cement-rubber chips. Int. J. Sustain. Constr. 2011, 1, 91-104.

109. Yang, R.C.; Li, K.; Zhu, J.P.; Zhu, T.K.; Dong, Z.; Wu, D.C. Effect of rubber particles on cement stabilized gravel system. J. Wuhan Univ. Technol. 2014, 29, 990-995. [CrossRef]

110. Yadav, J.S.; Tiwari, S.K. Evaluation of the strength characteristics of cement-stabilized clay-crumb rubber mixtures for its sustainable use in geotechnical applications. Environ. Dev. Sustain. 2018, 20, 1961-1985. [CrossRef]

111. Yadav, J.S.; Tiwari, S.K. A study on the potential utilization of crumb rubber in cement treated soft clay. J. Build. Eng. 2017, 9, 177-191. [CrossRef] 
112. Farhan, A.H.; Dawson, A.; Thom, N. Behaviour of rubberised cement-bound aggregate mixtures containing different stabilisation levels under static and cyclic flexural loading. Road Mater. Pavement 2020, 21, 2282-2301. [CrossRef]

113. Chan, C.M. Strength and stiffness of a cement-stabilised lateritic soil with granulated rubber addition. Proc. Inst. Civ. Eng. Gr. 2012, 165, 41-52. [CrossRef]

114. Wang, F.C.; Song, W. Effects of crumb rubber on compressive strength of cement-treated soil. Arch. Civ. Eng. 2015, 61, 59. [CrossRef]

115. Sun, X.Y.; Wu, S.Y.; Yang, J.; Yang, R.C. Mechanical properties and crack resistance of crumb rubber modified cement-stabilized macadam. Constr. Build. Mater. 2020, 259, 119708. [CrossRef]

116. Wang, Z.Y.; Mei, G.X. Dynamic properties of rubber cement stabilized soil based on resonant column tests. Mar. Georesour. Geotec. 2012, 30, 333-346. [CrossRef]

117. Otoko, G.R.; Pedro, P.P. Cement stabilization of Laterite and Chikoko soils using waste rubber fibre. Int. J. Eng. Sci. Res. Technol. 2014, 3, 130-136.

118. Bekhiti, M.; Trouzine, H.; Rabehi, M. Influence of waste tire rubber fibers on swelling behavior, unconfined compressive strength and ductility of cement stabilized bentonite clay soil. Constr. Build. Mater. 2019, 208, 304-313. [CrossRef]

119. Cao, D.W.; Ji, J.; Liu, Q.Q.; He, Z.Y.; Wang, H.N.; You, Z.P. Coal Gangue Applied to Low-Volume Roads in China. Transp. Res. Rec. 2011, 2024, 258-266. [CrossRef]

120. Sudla, P.; Donrak, J.; Hoy, M.; Horpibulsuk, S.; Arulrajah, A.; Rashid, A.S.A.; Nazir, R.; Samingthong, W. Laboratory investigation of cement-stabilized marginal Lateritic soil by crushed slag-fly ash replacement for pavement Applications. J. Mater. Civ. Eng. 2020, 32, 04019353. [CrossRef]

121. Autelitano, F.; Giuliani, F. Electric arc furnace slags in cement-treated materials for road construction: Mechanical and durability properties. Constr. Build. Mater. 2016, 113, 280-289. [CrossRef]

122. Sinha, A.K.; Havanagi, V.G.; Shahu, J.T. Stabilised jarofix waste material for road construction. Int. J. Pavement Eng. 2021, 22, 882-893. [CrossRef]

123. Lu, Q.Q. Strength enhancement and shrinkage reduction mechanism of desulfurized gypsum cement stabilized aggregates. J. Jilin Univ. (Technol. Ed.) 2021, 51, 252-258.

124. Xiao, J.; Long, C.J.; He, J.G.; Chang, J.; Wu, C.P.; Liu, C.Z.; Yan, W. Study on performance and micro characteristics of cement stabilized macadam with large amount of activated steel slag powder. China J. Highw. Transp. 2021. Available online: https: / / kns.cnki.net/kcms/detail/61.1313.U.20210708.0847.002.html (accessed on 12 October 2021).

125. Zhou, M.K.; Cheng, X.; Chen, X. Studies on the volumetric stability and mechanical properties of cement-fly-ash-stabilized steel slag. Materials 2021, 14, 495. [CrossRef]

126. You, L.Y.; Yue, Y.F.; Yan, K.Z.; Zhou, Y.B. Characteristics of cement-stabilized macadam containing surface-treated recycled aggregates. Road Mater. Pavement 2020, 22, 1-15. [CrossRef]

127. Ding, Y.H.; Wu, J.; Xu, P.; Zhang, X.G.; Fan, Y.H. Treatment methods for the quality improvement of recycled concrete aggregate (RCA)-A review. J. Wuhan Univ. Technol. 2021, 36, 77-92. [CrossRef]

128. Zhang, J.H.; Li, C.; Ding, L.; Zhao, H.G. Performance evaluation of strengthening recycled coarse aggregate in cement stabilized mixture base layer of pavement. Adv. Civ. Eng. 2020, 2020, 8821048.

129. Ouyang, K.; Shi, C.J.; Chu, H.Q.; Guo, H.; Song, B.X.; Ding, Y.H.; Guan, X.M.; Zhu, J.P.; Zhang, H.B.; Wang, Y.L.; et al. An overview on the efficiency of different pretreatment techniques for recycled concrete aggregate. J. Clean. Prod. 2020, 263, 121264. [CrossRef]

130. Li, Q.; Wen, H.M.; Li, G.F.; Ye, W.T.; Shang, J.L. Effects of strengthening methods and content of recycled aggregates on performance of cement stabilized macadam. J. Railw. Sci. Eng. 2021, 18, 1188-1195.

131. Yan, K.Z.; Li, G.K.; You, L.Y.; Zhou, Y.B.; Wu, S.H. Performance assessments of open-graded cement stabilized macadam containing recycled aggregate. Constr. Build. Mater. 2020, 233, 117326. [CrossRef]

132. Zhang, J.H.; Li, C.; Ding, L.; Li, J. Performance evaluation of cement stabilized recycled mixture with recycled concrete aggregate and crushed brick. Constr. Build. Mater. 2021, 296, 123596. [CrossRef]

133. Sun, Y.; Li, L.H. Strength assessment and mechanism analysis of cement stabilized reclaimed lime-fly ash macadam. Constr. Build. Mater. 2018, 166, 118-129. [CrossRef]

134. Del Valle-Zermeno, R.; Formosa, J.; Prieto, M.; Nadal, R.; Niubo, M.; Chimenos, J.M. Pilot-scale road subbase made with granular material formulated with MSWI bottom ash and stabilized APC fly ash: Environmental impact assessment. J. Hazard. Mater. 2014, 266, 132-140. [CrossRef]

135. Liu, D.; Li, L.; Cui, H. Pavement performance of cement stabilized municipal solid waste incineration bottom ash aggregate and crushed stones. J. Tongji U. (Nat. Sci.) 2015, 43, 405-409.

136. Sukmak, G.; Sukmak, P.; Horpibulsuk, S.; Yaowarat, T.; Kunchariyakun, K.; Patarapaiboolchai, O.; Arulrajah, A. Physical and mechanical properties of natural rubber modified cement paste. Constr. Build. Mater. 2020, 244, 118319. [CrossRef]

137. Mohammadi, I.; Khabbaz, H. Shrinkage performance of Crumb Rubber Concrete (CRC) prepared by water-soaking treatment method for rigid pavements. Cem. Concr. Comp. 2015, 62, 106-116. [CrossRef]

138. Chiaia, B.; Mier, J.G.M.V.; Vervuurt, A. Crack growth mechanisms in four different concretes: Microscopic observations and fractal analysis. Cem. Concr. Res. 1998, 28, 103-114. [CrossRef] 
139. Siddika, A.; Al Mamun, M.A.; Alyousef, R.; Amran, Y.H.M.; Aslani, F.; Alabduljabbar, H. Properties and utilizations of waste tire rubber in concrete: A review. Constr. Build. Mater. 2019, 224, 711-731. [CrossRef]

140. Li, Q.; Chen, J.H.; Hu, H.X. The tensile and swelling behavior of cement-stabilized marine clay reinforced with short waste fibers. Mar. Georesour. Geotec. 2019, 37, 1236-1246. [CrossRef]

141. Suleman, M.; Ahmad, N.; Khan, S.U.; Ahmad, T. Investigating flexural performance of waste tires steel fibers-reinforced cement-treated mixtures for sustainable composite pavements. Constr. Build. Mater. 2021, 275, 122099. [CrossRef]

142. Farhan, A.H.; Dawson, A.R.; Thom, N.H. Damage propagation rate and mechanical properties of recycled steel fiber-reinforced and cement-bound granular materials used in pavement structure. Constr. Build. Mater. 2018, 172, 112-124. [CrossRef]

143. Zhang, S.H.; Wang, Y.; Niu, D.T. Research progress of the application of waste fiber in cement-based materials. Mater. Rep. 2020, 34, 23042-23050.

144. Wang, Y.; Zhang, S.H.; Li, G.X.; Shi, X.M. Effects of alkali-treated recycled carbon fiber on the strength and free drying shrinkage of cementitious mortar. J. Clean. Prod. 2019, 228, 1187-1195. [CrossRef] 